\title{
Article
}

\section{Extraction behavior and separation of precious and base metals from chloride, bromide and iodide media using undiluted halide ionic liquids}

\author{
Willem Vereycken, Sofía Riaño, Tom Van Gerven, and Koen Binnemans
}

ACS Sustainable Chem. Eng., Just Accepted Manuscript • DOI: 10.1021/

acssuschemeng.0c01181 • Publication Date (Web): 07 May 2020

Downloaded from pubs.acs.org on May 12, 2020

\section{Just Accepted}

"Just Accepted" manuscripts have been peer-reviewed and accepted for publication. They are posted online prior to technical editing, formatting for publication and author proofing. The American Chemical Society provides "Just Accepted" as a service to the research community to expedite the dissemination of scientific material as soon as possible after acceptance. "Just Accepted" manuscripts appear in full in PDF format accompanied by an HTML abstract. "Just Accepted" manuscripts have been fully peer reviewed, but should not be considered the official version of record. They are citable by the Digital Object Identifier (DOI®). "Just Accepted" is an optional service offered to authors. Therefore, the "Just Accepted" Web site may not include all articles that will be published in the journal. After a manuscript is technically edited and formatted, it will be removed from the "Just Accepted" Web site and published as an ASAP article. Note that technical editing may introduce minor changes to the manuscript text and/or graphics which could affect content, and all legal disclaimers and ethical guidelines that apply to the journal pertain. ACS cannot be held responsible for errors or consequences arising from the use of information contained in these "Just Accepted" manuscripts. 


\section{Extraction behavior and separation of precious and base metals from chloride, bromide and iodide media using undiluted halide ionic liquids}

$\dagger$ KU Leuven, Department of Chemistry, Celestijnenlaan 200F, P.O. box 2404, B-3001 Leuven, Belgium.

$\star$ KU Leuven, Department of Chemical Engineering, Celestijnenlaan 200F, P.O. box 2424, B-3001 Leuven, Belgium.

*Corresponding author:

Email: Koen.Binnemans@kuleuven.be 
Abstract

Within the framework of metal separations and solvent extraction, chloride media are among the most studied systems. Bromide and iodide media have received much less attention, but can allow a different selectivity during the extraction. In present research, the extraction behavior of several precious and base metal ions, i.e. Pt(IV), $\mathrm{Pd}(\mathrm{II}), \mathrm{Rh}(\mathrm{III}), \mathrm{Au}(\mathrm{III}), \mathrm{Cu}(\mathrm{II}), \mathrm{Fe}(\mathrm{III})$ and $\mathrm{Ni}(\mathrm{II})$, from the different halide media was explored using the undiluted ionic liquid Aliquat 336 chloride and its bromide and iodide analogues. A single-step separation of Pt(IV) and Pd(II) from $\mathrm{Fe}(\mathrm{III})$ and $\mathrm{Ni}(\mathrm{II})$ was possible in the iodide system, but it was found to be incompatible with $\mathrm{Au}(\mathrm{III})$ and $\mathrm{Cu}(\mathrm{II})$. The chloride and bromide media showed potential for the separation of $\mathrm{Au}(\mathrm{III}), \mathrm{Pd}(\mathrm{II}), \mathrm{Fe}(\mathrm{III})$ and $\mathrm{Cu}(\mathrm{II})$, and their performance was subsequently compared. $\mathrm{Fe}(\mathrm{III})$ and $\mathrm{Cu}(\mathrm{II})$ were easily separated from $\mathrm{Au}(\mathrm{III})$ and $\mathrm{Pd}(\mathrm{II})$ via an extraction at low acid concentration followed by scrubbing with water for both systems. However, the stripping showed superior characteristics for the bromide system, where $\mathrm{Pd}(\mathrm{II})$ could be recovered using a $0.2 \mathrm{~mol} \mathrm{~L}^{-1}$ ammonia solution and $\mathrm{Au}(\mathrm{III})$ using $1.0 \mathrm{~mol} \mathrm{~L}^{-1}$ sodium sulfite. The proposed method for the separation of $\mathrm{Au}(\mathrm{III}), \mathrm{Pd}(\mathrm{II}), \mathrm{Fe}(\mathrm{III})$ and $\mathrm{Cu}(\mathrm{II})$ can be relevant for the recycling of waste electric and electronic equipment or analytical applications. The results highlight the importance of considering halides other than chloride as both the extraction and stripping properties of the system can be changed.

Keywords: Aliquat 336 halides; base metals; ionic liquids; precious metals; solvent extraction. 


\section{Introduction}

Solvent extraction is an established and powerful technique used in the separation and purification of metals. ${ }^{1}$ In conventional solvent extraction applications, metal separation is achieved by contacting a metal containing aqueous phase with an immiscible organic phase. The organic phase is generally comprised of a diluent and an extractant. Sometimes a modifier is added to change its physical properties. The extractant is an organic molecule designed to form metal complexes soluble in the organic phase. Because different metal ions show a different affinity for the extractant, they will distribute differently over both phases and separation can be achieved. In recent years, many research efforts have aimed to minimize the ecological impact of hydrometallurgical processes. Ionic liquids (ILs) are solvents consisting entirely out of ions and have been studied extensively as alternatives for volatile molecular solvents. ${ }^{2,3}$ They are characterized by a negligible vapor pressure, minimizing the risk of air pollution, and are electrically conductive excluding the risk of a build-up of static electricity in the solvent extraction plant. ${ }^{4}$ Ionic liquids are intrinsically highly tunable because of the near infinite amount of possible cation-anion combinations and are as such dubbed 'designer solvents'. Furthermore, they can act as basic extractants or anion exchangers and can extract metal ions from aqueous solutions. Undiluted ionic liquids have shown excellent selectivity and efficiency in several metal separation and purification applications, ranging from common base metals and rare earths to precious metals. For example, Wellens et al. reported the use of trihexyl(tetradecyl)phosphonium chloride (Cyphos IL 101) for the separation of Co(II) from $\mathrm{Ni}(\mathrm{II}), \mathrm{Mg}(\mathrm{II})$ and $\mathrm{Ca}(\mathrm{II})$ by extraction from $\mathrm{HCl}$ solutions. ${ }^{5}$ Riano et al. used trihexyl(tetradecyl)phosphonium nitrate (the nitrate form of Cyphos IL 101) for the recovery and separation of $\mathrm{Co}(\mathrm{II}), \mathrm{Nd}(\mathrm{III})$ and $\mathrm{Dy}(\mathrm{III})$ from $\mathrm{NdFeB}$ magnets. ${ }^{6}$ The separation and purification of $\mathrm{Pt}(\mathrm{IV}), \mathrm{Pd}(\mathrm{II})$ and $\mathrm{Rh}(\mathrm{III})$ from exhaust catalyst leachates using phosphonium ionic liquids has been studied by Firmansyah et al.. ${ }^{7,8}$ While ionic liquids offer many advantages 
for metal extraction applications, some disadvantages should be mentioned as well. Most notable are their relatively high cost, high viscosity and reduced mass transfer rate which are serious drawbacks for their large scale application.

Solvent extraction research has focused primarily on the conventional extraction media such as sulfates, chlorides and nitrates. Among the different halides, chloride media have received the most attention by far. The aqueous chloride chemistry of most metal ions and their extraction behavior to basic extractants such as ionic liquids has been studied quite extensively and is generally well known. ${ }^{9-11}$ Other halide media (i.e. bromide and iodide media) have received much less attention in the literature possibly because of their higher cost, reduced availability and as such lower industrial relevance. The extraction mechanism of basic extractants is generally described as an anion exchange process in which a negatively charged metal complex in the aqueous phase is exchanged for an anion in the organic phase:

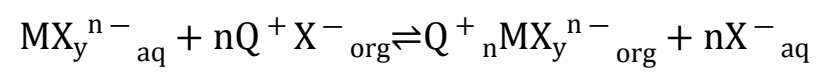

with $\mathrm{M}$ the respective metal, $\mathrm{X}^{-}$a coordinating anion (e.g. $\mathrm{Cl}^{-}, \mathrm{Br}^{-}$and $\left.\mathrm{I}^{-}\right)$and $\mathrm{Q}^{+}$an organic cation. However, recently some observations have shed doubt on this mechanism and a new model was put forward. ${ }^{11,12}$ The new model postulates that the species least stabilized by hydration is extracted to the organic phase. The extracted species can then undergo further Lewis acid-base adduct formation reactions forming negatively charged complexes which associate with the organic cations. Nevertheless, the extraction is promoted by the formation of negatively charged metal complexes making the concentration of the coordinating anion and the stability of the negatively charged complexes the main factors controlling whether extraction occurs or not. As such, a change in the applied halide medium can significantly affect 
the observed selectivity and allow enhanced or different metal separations in some cases. Nakamura and Ozawa, for example, found that the separation of $\mathrm{Cd}(\mathrm{II})$ from $\mathrm{Zn}$ (II) using tribenzylamine was enhanced when extracting from bromide or iodide media compared with the chloride medium. ${ }^{13}$ Sherif et al. showed that the separation of Ga(III) and In(III) using Adogen 364 was more efficient at lower acid concentration when working in $\mathrm{HBr}$ or $\mathrm{HI}$ media compared with the conventional $\mathrm{HCl}$ medium. ${ }^{14}$ Mojski et al. studied the extraction of $\mathrm{Au}(\mathrm{III})$, Pd(II) and Pt(IV) using di- $n$-octylsulfide from the different halide media and found Pt(IV) extraction to be only efficient from the iodide solutions. ${ }^{15}$

The interest in the alternative halide media is not limited to solvent extraction, they have also been put forward as safer and more sustainable leaching media for precious metals. In recent years, the pursuit of an alternative to the hazardous cyanide for the leaching of gold has been particularly popular. For example, Serpe et al. reported the recovery of gold from waste electric and electronic equipment (WEEE) using an aqueous mixture of $\mathrm{I}^{-} / \mathrm{I}_{2} \cdot{ }^{16}$ Birich et al. achieved a near-selective leaching of gold from random access memory (RAM) modules using a solution containing $2 \mathrm{wt} \% \mathrm{I}_{2}$ and $1.5 \mathrm{vol} \% \mathrm{H}_{2} \mathrm{O}_{2} \cdot{ }^{17}$ Sousa et al. studied the leaching of gold from ores with in-situ generated bromine using $\mathrm{NaOCl}, \mathrm{HCl}$ and $\mathrm{NaBr} .{ }^{18}$ In general, it is found that the bromine-based and iodine-based media show a higher leaching rate than cyanide solutions, being comparable to aqua regia. Moreover, they often show a higher selectivity for the separation of precious metals from base metals. ${ }^{19}$

In present paper, the influence of the choice of halide medium (i.e. chloride, bromide or iodide) on the extraction efficiency of Pt(IV), Pd(II), Rh(III), Au(III), Cu(II), Fe(III) and Ni(II) was explored using the undiluted ionic liquid Aliquat $336([\mathrm{~A} 336][\mathrm{Cl}])$ and its bromide and iodide analogues, $[\mathrm{A} 336][\mathrm{Br}]$ and $[\mathrm{A} 336][\mathrm{I}]$. Aliquat 336 is a commercially available ionic liquid and is comprised of a mixture of different quaternary ammonium chlorides, with trioctylmethylammonium chloride as the main component. The performed research aims to 
contribute to the knowledge of alternative solvent extraction media, but it also facilitates the development of new halide-based leaching processes by providing knowledge on the purification possibilities of the resultant pregnant leach solutions. The obtained results were subsequently applied to the development of a separation flowsheet for the purification of $\mathrm{Au}(\mathrm{III})$ and $\mathrm{Pd}(\mathrm{II})$ from a $\mathrm{Cu}(\mathrm{II})$ and $\mathrm{Fe}(\mathrm{III})$ rich solution. The developed flowsheet might find application in the recycling of waste electric and electronic equipment (WEEE) or in analytical purposes. 


\section{Experimental}

\section{Materials}

Aliquat $^{\circledR} 336, \mathrm{HI}(57 \mathrm{wt} \%), \mathrm{HBr}(48 \mathrm{wt} \%)$ and $\mathrm{NaOH}(\geq 99 \%)$ were purchased from Thermo Fisher Scientific (Merelbeke, Belgium). $\mathrm{NaBr}(\geq 99.5 \%), \mathrm{RhCl}_{3}(38 \mathrm{wt} \% \mathrm{Rh}), \mathrm{H}_{2} \mathrm{PtCl}_{6} \cdot 6 \mathrm{H}_{2} \mathrm{O}$ (99.9\%), $\mathrm{CuCl}_{2}$ (99\%), ethylenediaminetetraacetic acid disodium salt dihydrate $(\geq 99 \%)$, $\mathrm{Na}_{2} \mathrm{~S}_{2} \mathrm{O}_{3} \cdot 5 \mathrm{H}_{2} \mathrm{O}(\geq 99 \%)$ and $\left(\mathrm{NH}_{2}\right)_{2} \mathrm{CS}(\geq 99 \%)$ were acquired from Acros Organics (Geel, Belgium). $\mathrm{NaAuCl}_{4} \cdot 2 \mathrm{H}_{2} \mathrm{O}(99 \%), \mathrm{Na}_{2} \mathrm{SO}_{3}(\geq 98 \%)$, L-cysteine (97\%) and the gold standard (1000 $\mathrm{mg} \mathrm{L}^{-1}$ in $5 \mathrm{wt} \% \mathrm{HCl}$ ) were obtained from Sigma-Aldrich (Steinheim, Germany). $\mathrm{HNO}_{3}$ (65 wt $\%), \mathrm{NH}_{3}(25 \mathrm{wt} \%)$, the iron, gallium, copper, yttrium and nickel standards (1000 $\mathrm{mg} \mathrm{L}^{-1}$ in 2-5 $\left.\mathrm{wt} \% \mathrm{HNO}_{3}\right)$ and palladium, platinum and rhodium standards $\left(1000 \mathrm{mg} \mathrm{L}^{-1}\right.$ in $10-20 \mathrm{wt} \%$ $\mathrm{HCl}$ ) were purchased from Chem-Lab (Zedelgem, Belgium). $\mathrm{HCl}(37 \mathrm{wt} \%)$ was acquired from VWR (Leuven, Belgium). KI ( $\geq 99.5 \%$ ) and $\mathrm{FeCl}_{3}$ (99\%) were bought from Honeywell Riedel de Haën (Seelze, Germany). $\mathrm{PdCl}_{2}$ (99.9\%) was obtained from J\&K Scientific (Lommel, Belgium). $\mathrm{NiCl}_{2} \cdot 6 \mathrm{H}_{2} \mathrm{O}$ ( $\geq 98 \%$ ) was purchased from Merck Chemicals (Overijse, Belgium). Water was of ultrapure quality, deionized with a Merck Millipore Milli-Q ${ }^{\circledR}$ Reference A+ system. All chemicals were used as received, without any further purification.

\section{Instrumentation and analysis methods}

Aqueous metal concentrations were measured using a PerkinElmer Optima 8300 Inductively Coupled Plasma Optical Emission Spectrometer (ICP-OES) equipped with an axial/radial dual plasma view, a GemTip Cross-Flow II nebulizer, a Scott double pass with inert Ryton ${ }^{\circledR}$ spray chamber, a demountable one-piece Hybrid XLT ceramic torch with a $2.0 \mathrm{~mm}$ internal diameter sapphire injector, an echelle-based polychromator and a two-dimensional, segmented CCD 
array solid-state detector. In case of the chloride and bromide systems, samples were diluted with 2 vol\% $\mathrm{HNO}_{3}$ for the quantification of $\mathrm{Cu}(\mathrm{II}), \mathrm{Fe}(\mathrm{III}), \mathrm{Ni}(\mathrm{II}), \mathrm{Pt}(\mathrm{IV}), \mathrm{Pd}(\mathrm{II})$ and $\mathrm{Rh}(\mathrm{III})$. For the iodide system, samples were diluted with $2 \mathrm{vol} \% \mathrm{HCl}$ instead of $2 \mathrm{vol} \% \mathrm{HNO}_{3}$ to avoid the oxidation of the iodide ions to iodine by the nitrate ions. The measurement of $\mathrm{Au}(\mathrm{III})$ was complicated due to its adsorption to the sample introduction components of the ICP-OES equipment, which resulted in memory effects manifested by long wash-in and wash-out times. The samples for its quantification were therefore diluted with a solution containing 2 vol\% $\mathrm{HNO}_{3}, 2$ vol $\% \mathrm{HCl}$ and $0.5 \mathrm{wt} \% \mathrm{~L}$-cysteine. ${ }^{20,21}$ The additional complexing power of $\mathrm{HCl}$ and L-cysteine prevented the manifestation of the memory effect. Calibration was performed using solutions containing $0.1,1,5$ and $10 \mathrm{mg} \mathrm{L}^{-1}$ of the corresponding metal. All measurements were done in triplicate. A quality control was performed regularly using a solution containing $1 \mathrm{mg}$ $\mathrm{L}^{-1}$ metal. Y(III) and $\mathrm{Ga}(\mathrm{III})$ were added as internal standards $\left(5 \mathrm{mg} \mathrm{L}^{-1}\right)$, but were applied only in case matrix effects were observed. The experimental error calculated on the basis of triplicate measurements was less than 5\% and error bars on graphs were omitted for the sake of legibility. Measurement of the $\mathrm{pH}$ was performed using a Mettler-Toledo SevenCompact S220 system equipped with a Mettler-Toledo Inlab Micro pH electrode.

The purity and composition of the ionic liquids was qualitatively checked using total reflection X-ray fluorescence (TXRF) on a Bruker S2 Picofox TXRF, operated with a molybdenum source at $50 \mathrm{kV}$. Measurements were performed over $300 \mathrm{~s}$ on a $2 \mu \mathrm{L}$ ionic liquid droplet placed on a quartz sample carrier.

\section{Ionic liquid synthesis}

The bromide and iodide analogues of the ionic liquid $[\mathrm{A} 336][\mathrm{Cl}]$ were prepared through a salt metathesis reaction: 


$$
\mathrm{Q}^{+} \mathrm{Cl}^{-}{ }_{\text {org }}+\mathrm{X}^{-}{ }_{\text {aq }} \rightarrow \mathrm{Q}^{+} \mathrm{X}^{-}{ }_{\text {org }}+\mathrm{Cl}^{-}{ }_{\text {aq }}
$$

with $\mathrm{Q}^{+}$the quaternary ammonium cation and $\mathrm{X}^{-}$either the bromide or iodide anion.

A sample of $200 \mathrm{~mL}$ of [A336][Cl] was contacted 4 times with an equal volume of a 2 mol $\mathrm{L}^{-1}$ salt solution of the respective anion in a separatory funnel for 30 min using a RS-1 reciprocal shaker (JeioTech) operated at $250 \mathrm{rpm}$. $\mathrm{NaBr}$ and $\mathrm{KI}$ were used for the preparation of the bromide and iodide ionic liquids, respectively. The ionic liquids were then washed a for minimum of two times using an equal volume of ultrapure water to remove any dissolved salts. The absence of chloride ions was checked using a qualitative TXRF analysis (limit of detection $20 \mathrm{ppm} \mathrm{Cl).}{ }^{22}$ If found to be impure, the ionic liquids were subjected to additional contacts with the salt solution and additional washing steps.

\section{Metal extraction, scrubbing, stripping and quantification}

Extraction, scrubbing and stripping experiments were performed in $4 \mathrm{~mL}$ glass vials on a total liquid volume of $1 \mathrm{~mL}$, irrespective of the used organic-over-aqueous volume ratio $(\mathrm{O} / \mathrm{A})$. The loading of organic phases prior to scrubbing or stripping experiments was performed in 40 $\mathrm{mL}$ glass vials on a total liquid volume of $30 \mathrm{~mL}$. All experiments were executed by shaking laterally at $2500 \mathrm{rpm}$ for $60 \mathrm{~min}$ at room temperature using a TMS-200 Turbo Thermo Shaker (Allsheng Instruments). Phase separation was promoted by centrifugation for $3 \mathrm{~min}$ at 5000 rpm using a Heraeus Labofuge 200 centrifuge (Thermo Scientific).

Aqueous feed solutions were prepared by diluting a certain volume of an aqueous metal stock solution with ultrapure water and acid $(\mathrm{HCl} 37 \mathrm{wt} \%, \mathrm{HBr} 48 \mathrm{wt} \%$ or $\mathrm{HI} 57 \mathrm{wt} \%$, 
depending on the studied system) to obtain the desired metal and acid concentrations. The organic phases were saturated with water prior to any extraction, to exclude large volume changes during the extraction and to avoid subsequent incorrect evaluations of the experimental data.

Metal concentrations in aqueous phases were measured before and after extraction using ICP-OES, which allowed the calculation of the metal concentration in the organic phase using the mass balance:

$$
\mathrm{C}_{\mathrm{M}, \mathrm{org}, \mathrm{f}}=\frac{\mathrm{V}_{\mathrm{aq}}\left(\mathrm{C}_{\mathrm{M}, \mathrm{aq}, \mathrm{i}}-\mathrm{C}_{\mathrm{M}, \mathrm{aq}, \mathrm{f}}\right)}{\mathrm{V}_{\mathrm{org}}}
$$

with $\mathrm{C}_{\mathrm{M}, \text { org, }}$ the final concentration of metal $\mathrm{M}$ in the organic phase after extraction, $\mathrm{C}_{\mathrm{M}, \mathrm{aq}, \mathrm{i}}$ and $\mathrm{C}_{\mathrm{M} \text {,aq, }}$ the concentration of metal $\mathrm{M}$ in the aqueous phase before and after extraction, respectively, and $\mathrm{V}_{\mathrm{aq}}$ and $\mathrm{V}_{\text {org }}$ the volumes of the aqueous and organic phases, respectively. Extraction experiments were evaluated through the calculation of the extraction efficiency $\% E$ :

$$
\% E=\frac{\mathrm{V}_{\text {org }} \mathrm{C}_{\mathrm{M}, \text { org,f }}}{\mathrm{V}_{\mathrm{aq}} \mathrm{C}_{\mathrm{M}, \mathrm{aq}, \mathrm{i}}} * 100
$$

Similarly, scrubbing and stripping experiments were evaluated through the calculation of the scrubbing/stripping efficiency $\% S$ :

$$
\% S=\frac{\mathrm{V}_{\mathrm{aq}} \mathrm{C}_{\mathrm{M}, \mathrm{aq}, \mathrm{s}}}{\mathrm{V}_{\mathrm{org}} \mathrm{C}_{\mathrm{M}, \mathrm{org}, \mathrm{i}}} * 100
$$


1

2

3

4

5

6

7

8

9

10

11

12

13

14

15

16

17

18

19

20

21

22

23

24

25

26

27

28

29

30

31

32

33

34

35

36

37

38

39

40

41

42

43

44

45

46

47

48

49

50

51

52

53

54

55

56

57

58

59

60

with $\mathrm{C}_{\mathrm{M}, \mathrm{aq}, \mathrm{s}}$ the final concentration of metal $\mathrm{M}$ in the aqueous phase after scrubbing or stripping, and $\mathrm{C}_{\mathrm{M}, \text { org,i }}$ the concentration of metal $\mathrm{M}$ in the organic phase before scrubbing or stripping. 


\section{Results and discussion}

\section{Study of halide extraction media}

Because the aqueous bromide and iodide chemistry is much less studied, the extraction behavior and separation possibilities of several metals in such media was explored first and compared with the conventional chloride medium. For this, the conversion of the quaternary ammonium compound to its bromide or iodide form was required. If not performed prior to the extraction, the conversion will manifest itself during the extraction experiments. This in turn would result in a significant change in the composition of both the ionic liquid and aqueous phase during extraction and erroneous conclusions. The occurrence of anion exchange can be predicted by considering the Hofmeister series $\left(\mathrm{SO}_{4}{ }^{2-}<\mathrm{Cl}^{-}<\mathrm{Br}^{-}<\mathrm{NO}_{3}{ }^{-}<\mathrm{I}^{-}<\mathrm{ClO}_{4}{ }^{-}<\mathrm{SCN}^{-}\right)$. Anions at the left side of the series are characterized by a high charge density and hydration is favored over association with the quaternary ammonium cation. As such, when an ionic liquid of a certain anion is contacted with an aqueous phase containing an anion more to the right in the series, an exchange will occur. ${ }^{23,24}$ Some exchange is also expected when the ionic liquid is contacted with an excess of an anion positioned more to the left side of the series, since the involved exchange reaction is an equilibrium. The properties of the synthesized, water-saturated bromide and iodide analogues of [A336][Cl] are reported in Table S1 (Supporting Information).

Extraction experiments were performed using undiluted [A336][Cl], [A336][Br] and [A336][I], and aqueous multi-element solutions containing $200 \mathrm{mg} \mathrm{L}^{-1} \mathrm{Pt}(\mathrm{IV}), \mathrm{Pd}(\mathrm{II}), \mathrm{Rh}(\mathrm{III})$, $\mathrm{Au}(\mathrm{III}), \mathrm{Cu}(\mathrm{II}), \mathrm{Fe}(\mathrm{III})$ and $\mathrm{Ni}(\mathrm{II})$ with varying hydrohalic acid ( $\mathrm{HCl}, \mathrm{HBr}$ and $\mathrm{HI}$, respectively) concentrations. Note that in all cases the used stock solutions were based on the chloride salts of the involved metals and that minor amounts of chloride ions were thus present during the study of the bromide and iodide systems. This should, however, not cause any issues as for all studied metal and acid concentrations, the respective anion (i.e. $\mathrm{Br}^{-}$or $\mathrm{I}^{-}$) was present in excess. 
Moreover, for most practical applications of bromide or iodide systems such as the leaching of precious metals using bromine or iodine, some amount of chloride ions would be present to constrain the cost of the process and to allow for a sufficient solubility of the metals involved. ${ }^{18,25,26}$ Figure 1 displays the extraction efficiency of $\mathrm{Pt}(\mathrm{IV}), \mathrm{Pd}(\mathrm{II}), \mathrm{Rh}(\mathrm{III}), \mathrm{Au}(\mathrm{III})$, $\mathrm{Cu}(\mathrm{II}), \mathrm{Fe}(\mathrm{III})$ and $\mathrm{Ni}(\mathrm{II})$ by the undiluted ionic liquids [A336][Cl], [A336][Br] and [A336][I], as a function of the halide concentration which was varied using $\mathrm{HCl}, \mathrm{HBr}$ and $\mathrm{HI}$, respectively. 
(a) $\mathrm{Pt}(\mathrm{IV})$

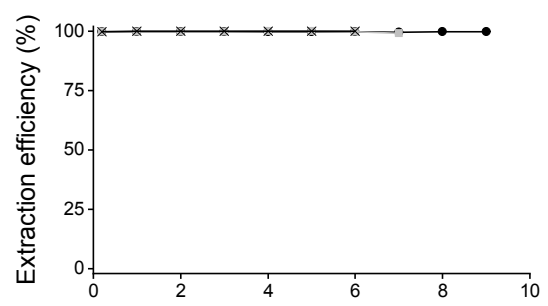

(c) $\mathrm{Rh}(\mathrm{III})$

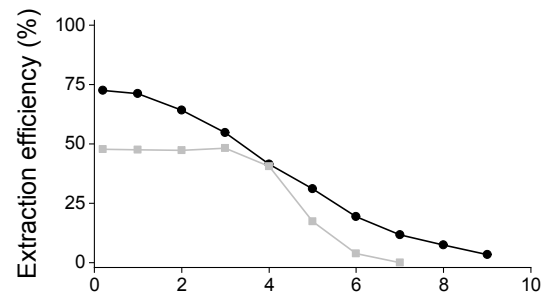

(e) $\mathrm{Cu}(\mathrm{II})$

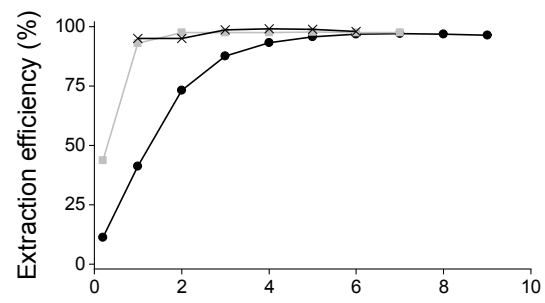

(g) $\mathrm{Au}(\mathrm{III})$

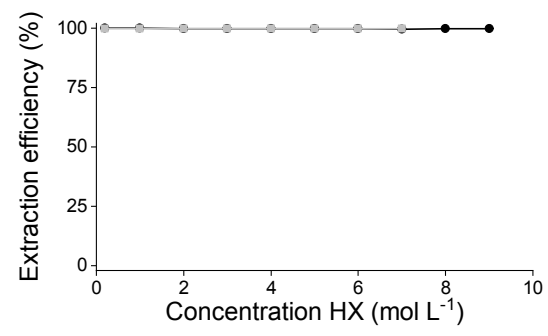

(b) $\operatorname{Pd}($ II)

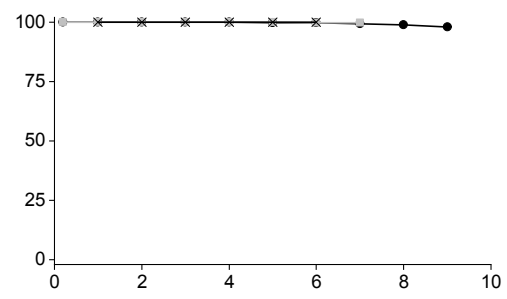

(d) $\mathrm{Fe}(\mathrm{III})$

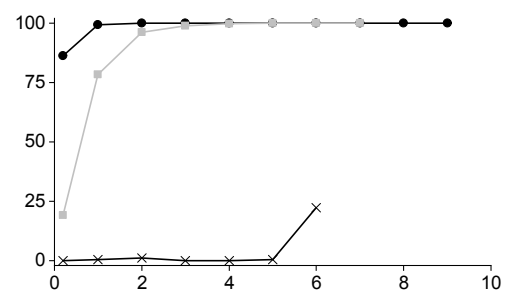

(f) $\mathrm{Ni}(\mathrm{II})$

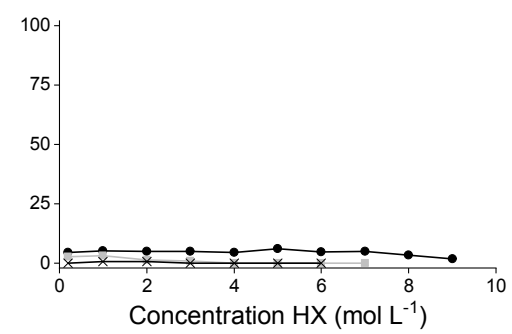

Figure 1: Extraction efficiency of $200 \mathrm{mg} \mathrm{L}^{-1} \mathrm{Pt}(\mathrm{IV}), \mathrm{Pd}(\mathrm{II}), \mathrm{Rh}(\mathrm{III}), \mathrm{Au}(\mathrm{III}), \mathrm{Cu}(\mathrm{II}), \mathrm{Fe}(\mathrm{III})$ and $\mathrm{Ni}(\mathrm{II})$ towards $[\mathrm{A336}][\mathrm{Cl}](\bullet),[\mathrm{A336}][\mathrm{Br}](\square)$ and $[\mathrm{A336}][\mathrm{II}(\boldsymbol{X})$, as a function of the HX concentration (HCl, $\mathrm{HBr}$ and $\mathrm{HI}$, respectively). For [A336][I], Au(III) and Rh(III) are not shown due to solubility issues. Conditions: $2500 \mathrm{rpm}$, $60 \mathrm{~min}$, room temperature, $O / A=1$. 
For $[\mathrm{A} 336][\mathrm{Cl}]$ and $[\mathrm{A} 336][\mathrm{Br}]$, a similar trend was observed. Pt(IV), Pd(II) and $\mathrm{Au}(\mathrm{III})$ easily form anionic complexes, even at low halide concentrations and they were quantitatively extracted over the entire concentration range (Figure 1 (a), (b) and (g)). The extraction efficiency of $\mathrm{Rh}$ (III) showed a decreasing trend with the acid concentration (Figure 1 (c)). For the chloride system, this can be related to the shift from the $\left[\mathrm{RhCl}_{5}\left(\mathrm{H}_{2} \mathrm{O}\right)\right]^{2-}$ complex at low chloride concentrations to the $\left[\mathrm{RhCl}_{6}\right]^{3-}$ complex at higher chloride concentrations. The latter is hydrated to a greater extent and thus extracted less efficiently. ${ }^{27-29} \mathrm{~A}$ similar explanation seems to fit for the bromide system although no speciation data could be found in the literature for comparison. $\mathrm{Rh}$ (III) displays a higher affinity for bromide than for chloride and it can be expected that the hydrated $\left[\mathrm{RhBr}_{6}\right]^{3-}$ complex occurs already at lower halide concentrations. ${ }^{30}$ Consequently, the extraction efficiency of $\mathrm{Rh}(\mathrm{III})$ is overall lower in the bromide medium. Both $\mathrm{Cu}(\mathrm{II})$ and $\mathrm{Fe}(\mathrm{III})$ showed an increase in extraction efficiency with increasing acid concentration (Figure 1 (d) and (e)). For the chloride system, Fe(III) was extracted more efficiently (i.e. reached complete extraction at a lower acid concentration) than $\mathrm{Cu}(\mathrm{II})$, while for the bromide system, $\mathrm{Cu}(\mathrm{II})$ was extracted more efficiently than $\mathrm{Fe}(\mathrm{III})$. This inversion in extraction efficiency can be related to the stability of their anionic halide complexes. In a chloride medium, $\mathrm{Fe}(\mathrm{III})$ complexes are generally more stable than $\mathrm{Cu}$ (II) complexes (first complexation constants $\mathrm{K}_{1, \mathrm{Cl}}(\mathrm{Fe}(\mathrm{III}))=4.3$ and $\mathrm{K}_{1, \mathrm{Cl}}(\mathrm{Cu}(\mathrm{II}))=1.2$ at ionic strength (I) 1 and 2 respectively). While for a bromide medium, the inverse is true $\left(\mathrm{K}_{1, \mathrm{Br}}(\mathrm{Fe}(\mathrm{III}))=0.75\right.$ and $\mathrm{K}_{1, \mathrm{Cl}}(\mathrm{Cu}(\mathrm{II}))=0.95$ at $\mathrm{I}=1$ and 2 respectively). ${ }^{31,32}$ This can also be understood more qualitatively as $\mathrm{Cu}(\mathrm{II})$ is a softer Lewis acid than $\mathrm{Fe}(\mathrm{III})$ and tends to associate more easily with bromide. Ni(II) extraction is inefficient in both systems (Figure 1 (f)), which results from the low tendency of $\mathrm{Ni}(\mathrm{II})$ to form anionic halide complexes. ${ }^{33}$ 
For [A336][I], $\mathrm{Au}(\mathrm{III})$ was not included in the experiments as it was found to be unstable at the used conditions due to its reduction to metallic gold. The involved redox half reactions are displayed in Equation 6 and Equation 7. ${ }^{34-36}$ The presence of an oxidizing agent (e.g. $\mathrm{H}_{2} \mathrm{O}_{2}$ ) seems to be a prerequisite for the stability of $\mathrm{Au}(\mathrm{III})$ in iodide solutions. ${ }^{17}$ Further in-depth investigation of $\mathrm{Au}(\mathrm{III})$ was outside the scope of this study.

$$
\begin{array}{cc}
\mathrm{AuI}_{4}{ }^{-}+3 \mathrm{e}^{-} \rightarrow \mathrm{Au}+4 \mathrm{I}^{-} & \mathrm{E}^{0}=+0.56 \mathrm{~V} \\
\mathrm{I}_{3}{ }^{-}+2 \mathrm{e}^{-} \rightarrow 3 \mathrm{I}^{-} & \mathrm{E}^{0}=+0.54 \mathrm{~V}
\end{array}
$$

Also $\mathrm{Rh}(\mathrm{III})$ was not included because of the very low solubility of $\mathrm{RhI}_{3}$ in aqueous media and the fact that $\mathrm{Rh}(\mathrm{III})$ does not form anionic iodide complexes. ${ }^{37}$ Moreover, both $\mathrm{Pd}(\mathrm{II})$ and $\mathrm{Cu}$ (II) showed solubility issues at the lowest acid concentration of $0.2 \mathrm{~mol} \mathrm{~L}-1$ HI. $\mathrm{PdI}_{2}$ is known to show a limited solubility if only a small excess of iodide is present. ${ }^{38}$ For copper, the precipitation of $\mathrm{Cu}(\mathrm{I})$ iodide as described in Equation 8 occurs at low iodide concentrations, while at higher concentrations soluble copper complexes such as $\left[\mathrm{CuI}_{2}\right]^{-}$can be formed. ${ }^{39-41}$

$$
\mathrm{Cu}^{2+}+2 \mathrm{I}^{-} \rightarrow \mathrm{CuI} \downarrow+1 / 2 \mathrm{I}_{2} \quad \mathrm{~K}_{\mathrm{sp}}(\mathrm{CuI})=1 \cdot 10^{-12}
$$

Figure 1 (a), (b) and (f) show that, just as for the chloride and the bromide systems, $\operatorname{Pd}(\mathrm{II})$ and $\mathrm{Pt}(\mathrm{IV})$ were extracted quantitatively and $\mathrm{Ni}(\mathrm{II})$ was not extracted over the entire concentration range. In contrast to $[\mathrm{A} 336][\mathrm{Cl}]$ and $[\mathrm{A} 336][\mathrm{Br}]$, the extraction of both copper and iron was nearly independent of the applied acid concentration in the iodide system. Fe(III) was reduced to $\mathrm{Fe}(\mathrm{II})$ and was not extracted due to its low tendency to form anionic iodide complexes (Figure 1 (d)). ${ }^{42}$ At the highest iodide concentration, some extraction was observed. 
Copper, being a softer Lewis acid and interacting more easily with iodide, is most likely present as anionic $\mathrm{Cu}(\mathrm{I})$ iodide complexes that are easily extracted (Figure 1 (e)).

The preceding results indicate that the different Aliquat 336 halides and halide media show promising characteristics for the separation of several precious metals (i.e. $\mathrm{Au}(\mathrm{III}), \mathrm{Pd}(\mathrm{II})$ and $\mathrm{Pt}(\mathrm{IV})$ ) from common base metals (i.e. $\mathrm{Fe}(\mathrm{III}), \mathrm{Cu}(\mathrm{II})$ and $\mathrm{Ni}(\mathrm{II})$ ). In the chloride and bromide system, the precious metals were extracted quantitatively, while the extraction of the base metals showed a dependence on the acid/halide concentration. This allows for the development of a separation procedure with selectivity during extraction, but also indicates that selective scrubbing is possible. Even though the iodide system displayed some issues with $\mathrm{Au}(\mathrm{III})$ and $\mathrm{Rh}(\mathrm{III})$, it still remains a valid option for some specific separations as it allows for a very efficient, single-step separation between the precious metal ions $\mathrm{Pd}(\mathrm{II})$ or $\mathrm{Pt}(\mathrm{IV})$ and the base metal ions $\mathrm{Fe}(\mathrm{II})$ or $\mathrm{Ni}(\mathrm{II})$ without any coextraction of both base metals.

\section{Extraction of $\mathrm{Au}(\mathrm{III})$ and $\mathrm{Pd}(\mathrm{II})$ from a $\mathrm{Cu}(\mathrm{II})$ and $\mathrm{Fe}$ (III) rich solution}

The insights obtained in the previous section were applied to develop a solvent extraction separation flowsheet for the treatment of a feed solution containing both precious and base metals. Precious metals and base metals are often found together in their applications. The bestknown example in today's society is without doubt electric and electronic equipment. Waste electric and electronic equipment (WEEE) is one of the largest and fastest growing waste streams worldwide, between 40 and 50 million tons is generated each year with an annual growth rate of 3-5\%. ${ }^{43-45}$ Proper handling and recycling of this rapidly growing waste stream is imperative for both the environment and human health but can also be interesting from an economical point of view, as it can be an important source of both base and precious metals..$^{25,46-}$

${ }^{49}$ WEEE can contain a whole range of metals but iron and copper are its main constituents by weight. The precious metals gold and palladium are present in only minor amounts, even in 
high grade scrap, but they represent $70-80 \%$ of the value share..$^{43,49,50}$ In the following paragraphs, a separation flowsheet will be developed for $\mathrm{Au}(\mathrm{III}), \mathrm{Pd}(\mathrm{II}), \mathrm{Cu}(\mathrm{II})$ and $\mathrm{Fe}(\mathrm{III})$. It was not our aim to develop a new processing method for WEEE leachates. The WEEE case study was only used as a guideline in deciding which metals were studied and in what relative concentrations.

The iodide system appeared to be unsuitable for the separation of $\mathrm{Au}$ (III) from $\mathrm{Cu}$ (II) due to the reduction of $\mathrm{Au}(\mathrm{III})$ to $\mathrm{Au}(0)$ and the risk of $\mathrm{CuI}$ precipitation. Comparing the chloride and the bromide system, $\mathrm{Cu}(\mathrm{II})$ is least efficiently extracted in the chloride medium, while for $\mathrm{Fe}(\mathrm{III})$ the extraction is less efficient in the bromide system. Consequently, the separation of $\mathrm{Au}(\mathrm{III})$ and $\mathrm{Pd}(\mathrm{II})$ from $\mathrm{Cu}(\mathrm{II})$ is expected to be more efficient using the chloride system, while for the separation of $\mathrm{Au}(\mathrm{III})$ and $\mathrm{Pd}(\mathrm{II})$ from $\mathrm{Fe}(\mathrm{III})$ the bromide system is preferred. For this reason, two different model solutions were prepared. The used metal ratios are shown in Table 1 and are loosely based on reports of WEEE composition found in the literature. ${ }^{50}$

Table 1: Metal concentrations of the used model feed solutions compared with composition of PC board scrap. ${ }^{50}$

\begin{tabular}{lllll}
\hline & $\mathrm{Cu}$ & $\mathrm{Fe}$ & $\mathrm{Au}$ & $\mathrm{Pd}$ \\
\hline $\begin{array}{l}\text { Feed solution } \\
\text { chloride medium }\left(\mathrm{mg} \mathrm{L}^{-1}\right)\end{array}$ & 10000 & 3300 & 50 & 25 \\
$\begin{array}{l}\text { Feed solution } \\
\text { bromide medium }\left(\mathrm{mg} \mathrm{L}^{-1}\right)\end{array}$ & 3300 & 10000 & 50 & 25 \\
PC board scrap (wt\%) & 20 & 7 & 0.025 & 0.011 \\
\hline
\end{tabular}

For the extraction of both feed solutions with [A336][Cl] and [A336][Br], the influence of acid concentration and $\mathrm{O} / \mathrm{A}$ ratio was studied. The influence of acid concentration $(\mathrm{HCl}$ and $\mathrm{HBr}$, respectively for the chloride and bromide systems) at a constant $\mathrm{O} / \mathrm{A}$ volume ratio of 1 , is 
shown in Figure 2. Similar to Figure 1, Au(III) was extracted quantitatively, independent of the acid concentration in both systems. The extraction of $\mathrm{Pd}(\mathrm{II})$ towards [A336][Cl] was not as efficient at low $\mathrm{HCl}$ concentrations as expected from Figure 1, with an extraction efficiency of $95 \%$ in the absence of $\mathrm{HCl}$. This was possibly caused by a competition with the strongly extracted $\mathrm{Fe}(\mathrm{III})$, which is present in a high concentration. Complete extraction of $\mathrm{Pd}(\mathrm{II})$ was achieved at $2 \mathrm{~mol} \mathrm{~L}^{-1} \mathrm{HCl}$. For the bromide system, such a competition was not observed and Pd(II) was extracted quantitatively, even at low acid concentrations. This is the result of the significantly higher stability constants of the $\operatorname{Pd}(\mathrm{II})$ bromo complexes compared to its corresponding chloro complexes (overall stability constants of $\mathrm{Pd}(\mathrm{II})$ halide complexes: $\left.\beta_{4}\left(\left[\mathrm{PdCl}_{4}\right]^{2-}\right)=10^{11.54} ; \beta_{4}\left(\left[\mathrm{PdBr}_{4}\right]^{2-}\right)=10^{14.94}\right) .{ }^{51}$ Small losses of $\mathrm{Pd}(\mathrm{II})$ during the extraction stage can affect the economic achievability of the entire metallurgical flowsheet. The slightly inefficient extraction of $\mathrm{Pd}(\mathrm{II})$ to $[\mathrm{A} 336][\mathrm{Cl}]$ at low $\mathrm{HCl}$ concentrations could be resolved by performing a multi-stage extraction. However, this would also result in an increased $\mathrm{Cu}(\mathrm{II})$ and $\mathrm{Fe}(\mathrm{III})$ extraction and as such a less efficient separation. Moreover, it would result in a significantly larger footprint of the entire process.

For both systems, the extraction efficiency of $\mathrm{Cu}(\mathrm{II})$ and $\mathrm{Fe}(\mathrm{III})$ showed an increase with acid concentration for the studied concentration range. As expected based on Figure 1, the extraction of $\mathrm{Cu}(\mathrm{II})$ was more efficient in the bromide system, while for $\mathrm{Fe}(\mathrm{III})$ extraction was more efficient in the chloride system. Preferably, the extraction of both $\mathrm{Cu}(\mathrm{II})$ and $\mathrm{Fe}(\mathrm{III})$ is minimal such that their subsequent scrubbing would be less extensive. An extraction in the absence of acid (i.e. $0 \mathrm{~mol} \mathrm{~L}^{-1} \mathrm{HCl}$ or $\mathrm{HBr}$ ) would therefore be optimal. In practice, however, leachates do contain some amount of unreacted acid and/or salts that would result in an increased $\mathrm{Cu}(\mathrm{II})$ and $\mathrm{Fe}(\mathrm{III})$ extraction efficiency and a lowered precious and base metal separation. For this reason, it was chosen to proceed with a non-zero acid concentration of 0.5 mol L-1 $\mathrm{HCl}$ or $\mathrm{HBr}$, respectively. 
Using this acid concentration of $0.5 \mathrm{~mol} \mathrm{~L}^{-1}$, the influence of the $\mathrm{O} / \mathrm{A}$ volume ratio on the extraction efficiency was studied for both systems. The results are shown in Figure 3. The extraction efficiencies of $\mathrm{Au}(\mathrm{III})$ and $\mathrm{Pd}(\mathrm{II})$ remained unaffected, which highlights again their efficient extraction (even at a low acid concentrations) and strong affinity for the organic phase. For $\mathrm{Cu}(\mathrm{II})$ and $\mathrm{Fe}(\mathrm{III})$, the extraction efficiency decreased when working at small $\mathrm{O} / \mathrm{A}$ volume ratios. Decreasing the $\mathrm{O} / \mathrm{A}$ volume ratio is not only beneficial for the suppression of $\mathrm{Cu}(\mathrm{II})$ and $\mathrm{Fe}(\mathrm{III})$ extraction, but it also results in a concentration of the valuable $\mathrm{Au}(\mathrm{III})$ and $\mathrm{Pd}(\mathrm{II})$ in the organic phase and minimizes the use of the expensive ionic liquids. In an ideal case, the volume of the ionic liquid phase would be reduced to such an extent that only $\mathrm{Au}(\mathrm{III})$ and $\mathrm{Pd}(\mathrm{II})$ are loaded and highly concentrated. The ionic liquid could then be seen as a scavenger of Au(III) and $\mathrm{Pd}(\mathrm{II})$. However, such small $\mathrm{O} / \mathrm{A}$ volume ratios are not practically feasible in industrial solvent extraction infrastructure such as mixer-settlers. For practical reasons, the O/A volume ratio of choice was $1 / 3$, which allowed sufficient volume of both phases. 
(a)

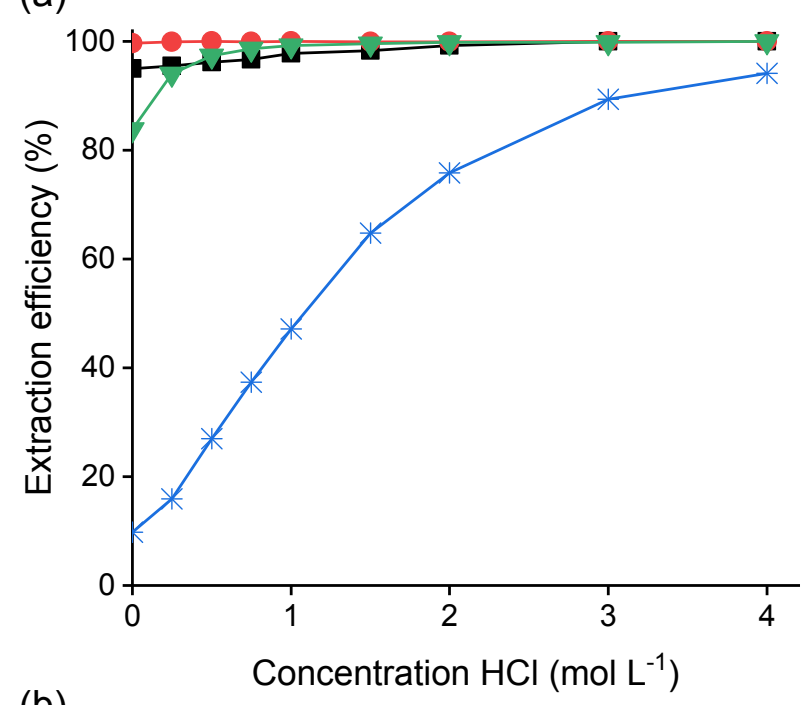

(b)

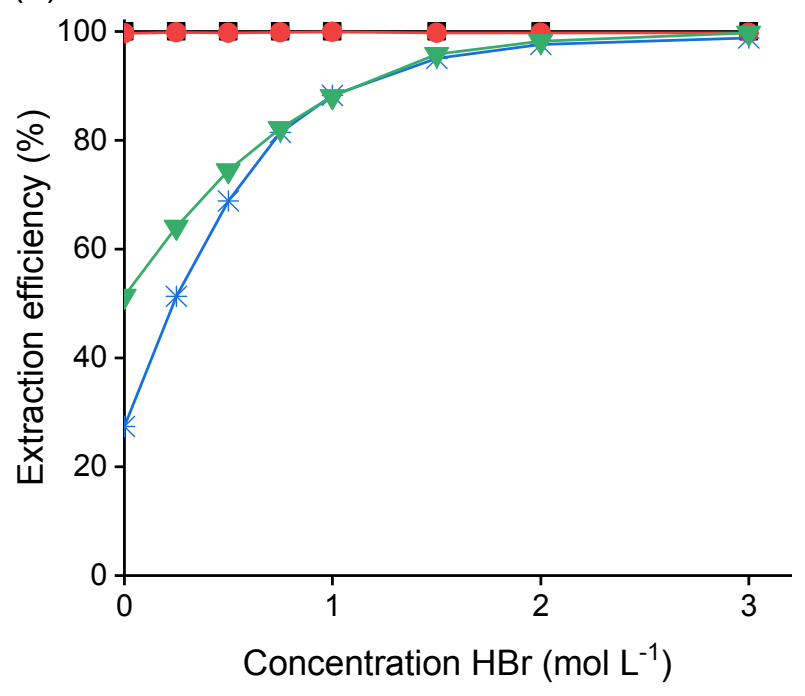

Figure 2: (a) Extraction efficiency of $25 \mathrm{mg} \mathrm{L}^{-1} \mathrm{Pd}(\mathrm{II})$ (घ), $50 \mathrm{mg} \mathrm{L}^{-1} \mathrm{Au}(\mathrm{III})(\bullet), 10000$ $m g L^{-1} \mathrm{Cu}(I I)$ (*) and $3300 \mathrm{mg} \mathrm{L}^{-1} \mathrm{Fe}(\mathrm{III})(\nabla)$ towards [A336][Cl] as a function of the $\mathrm{HCl}$ concentration; and (b) extraction efficiency of $25 \mathrm{mg} \mathrm{L}^{-1} \mathrm{Pd}(\mathrm{II})$ (ロ), $50 \mathrm{mg} \mathrm{L}^{-1} \mathrm{Au}(\mathrm{III})(\bullet)$, $3300 \mathrm{mg} \mathrm{L}^{-1} \mathrm{Cu}(\mathrm{II})(*)$ and $10000 \mathrm{mg} \mathrm{L} \mathrm{L}^{-1} \mathrm{Fe}(\mathrm{III})(\mathrm{\nabla})$ towards [A336][Br] as a function of the $\mathrm{HBr}$ concentration. Conditions: $2500 \mathrm{rpm}, 60 \mathrm{~min}$, room temperature, $\mathrm{O} / \mathrm{A}=1$. 
(a)

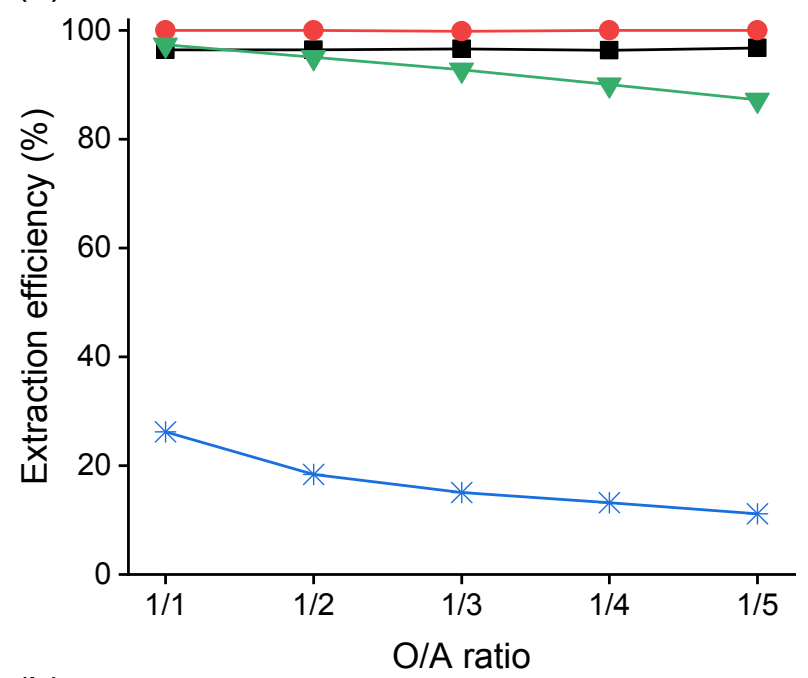

(b)

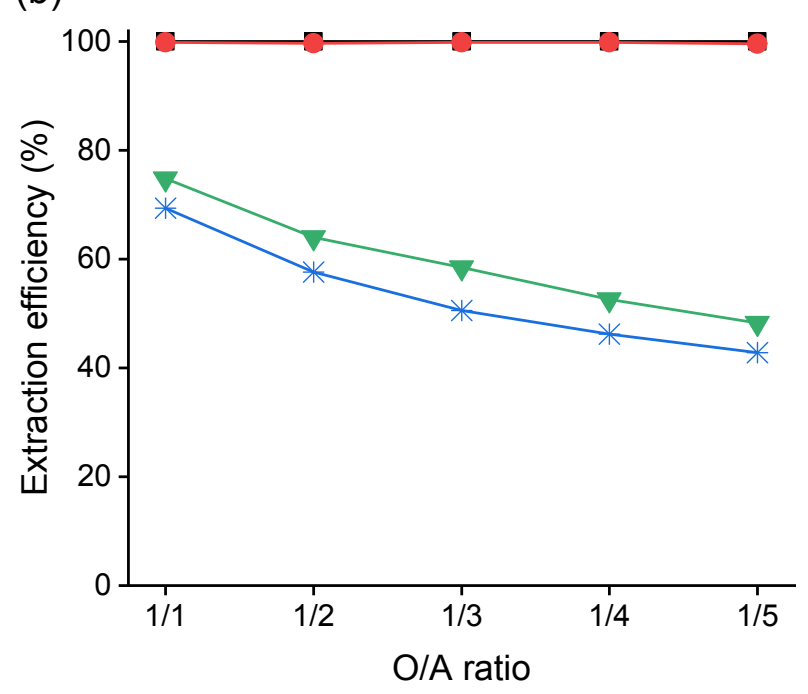

Figure 3: (a) Extraction efficiency of $25 \mathrm{mg} \mathrm{L} \mathrm{L}^{-1} \mathrm{Pd}(\mathrm{II})(\mathbf{\bullet}), 50 \mathrm{mg} \mathrm{L}^{-1} \mathrm{Au}(\mathrm{III})(\bullet), 10000$ $m g L^{-1} \mathrm{Cu}(\mathrm{II})$ (*) and $3300 \mathrm{mg} \mathrm{L}^{-1} \mathrm{Fe}(I I I)(\nabla)$ towards [A336][Cl] as a function of the O/A volume ratio using $0.5 \mathrm{~mol} \mathrm{~L}^{-1} \mathrm{HCl}$; and (b) extraction efficiency of $25 \mathrm{mg} \mathrm{L}^{-1} \mathrm{Pd}(\mathrm{II})$ (-), 50 $m g L^{-1} \mathrm{Au}(I I I)(\bullet), 3300 \mathrm{mg} \mathrm{L}^{-1} \mathrm{Cu}(\mathrm{II})$ (*) and $10000 \mathrm{mg} \mathrm{L}^{-1} \mathrm{Fe}(\mathrm{III})$ ( $\left.\mathbf{\nabla}\right)$ towards [A336] [Br] as a function of the O/A volume ratio using $0.5 \mathrm{~mol} \mathrm{~L} \mathrm{~L}^{-1} \mathrm{HBr}$. Conditions: 2500 rpm, $60 \mathrm{~min}$, room temperature. 
The co-extraction of $\mathrm{Cu}(\mathrm{II})$ and $\mathrm{Fe}(\mathrm{III})$ towards [A336][Cl] and [A336][Br] can be suppressed by working at low acid or halide concentrations and small O/A volume ratios, but cannot be entirely excluded while working at realistic conditions (vide supra). Yet, the coextracted $\mathrm{Cu}(\mathrm{II})$ and $\mathrm{Fe}(\mathrm{III})$ can be removed from the organic phase through a scrubbing operation. As the observed trends for the extraction efficiency in Figure 1 and Figure 2 suggest, the scrubbing of $\mathrm{Cu}(\mathrm{II})$ and $\mathrm{Fe}(\mathrm{III})$ is favorable at low acid concentrations or in the absence of acid using water. The latter was studied on $[\mathrm{A} 336][\mathrm{Cl}]$ and $[\mathrm{A} 336][\mathrm{Br}]$ loaded with $\mathrm{Au}(\mathrm{III})$, $\mathrm{Pd}(\mathrm{II}), \mathrm{Cu}(\mathrm{II})$ and $\mathrm{Fe}(\mathrm{III})$ using the previously optimized parameters $\left(0.5 \mathrm{~mol} \mathrm{~L}^{-1} \mathrm{HCl}\right.$ or $\mathrm{HBr}$ and $\mathrm{O} / \mathrm{A} 1 / 3$ ). The influence of the $\mathrm{O} / \mathrm{A}$ ratio on the scrubbing efficiency of $\mathrm{Cu}(\mathrm{II})$ and $\mathrm{Fe}(\mathrm{III})$ is shown in Figure 4. No $\mathrm{Au}(\mathrm{III})$ or Pd(II) was detected in the scrub solutions (the ICP-OES limits of detection are respectively $0.1-1$ and 1-10 ppb). For the chloride system, the scrubbing efficiency of $\mathrm{Fe}(\mathrm{III})$ steadily increased with a decreasing $\mathrm{O} / \mathrm{A}$ volume ratio, while $\mathrm{Cu}(\mathrm{II})$ reached complete scrubbing at a $\mathrm{O} / \mathrm{A}$ volume ratio of $1 / 3$. In case of the bromide system, a similar trend was observed. The scrubbing efficiency of Fe(III) steadily increased with a decreasing $\mathrm{O} / \mathrm{A}$ volume ratio. However, the efficiencies were higher than those of the chloride system i.e. Fe(III) was more easily scrubbed from the bromide ionic liquid. $\mathrm{Cu}(\mathrm{II})$ reached complete scrubbing at an $\mathrm{O} / \mathrm{A}$ ratio of $1 / 4$. For the same practical reason as before, the $\mathrm{O} / \mathrm{A}$ ratio of choice is $1 / 3$.

As Figure 4 shows, a single scrubbing stage using a O/A ratio of 1/3 could not result in the quantitative removal of both $\mathrm{Cu}(\mathrm{II})$ and $\mathrm{Fe}(\mathrm{III})$. The loaded organic phases were therefore subjected to three sequential scrubbing stages using pure water in an $\mathrm{O} / \mathrm{A}$ volume ratio of 1/3. Table 2 includes the metal concentrations in the scrub solutions and the cumulative scrubbing 
efficiencies. $\mathrm{Cu}(\mathrm{II})$ was completely scrubbed in two stages from both ionic liquids. For Fe(III), a third stage was required to remove the last traces. The absence of $\mathrm{Cu}(\mathrm{II})$ and $\mathrm{Fe}(\mathrm{III})$, and the presence of $\mathrm{Au}(\mathrm{III})$ and $\mathrm{Pd}(\mathrm{II})$ in both scrubbed ionic liquids was qualitatively confirmed using TXRF analyses (Supporting Information, Figure S1 and S2).

In conclusion, a complete separation between the base metals $\mathrm{Cu}(\mathrm{II})$ and $\mathrm{Fe}(\mathrm{II})$ and the precious metals $\mathrm{Au}(\mathrm{III})$ and $\mathrm{Pd}(\mathrm{II})$ was achieved through selectivity during both the extraction and scrubbing stages. The result is an organic phase loaded with both $\mathrm{Au}(\mathrm{III})$ and $\mathrm{Pd}(\mathrm{II})$ while $\mathrm{Cu}(\mathrm{II})$ and $\mathrm{Fe}(\mathrm{III})$ are collected in the aqueous raffinate and scrubbing solutions. In conventional hydrometallurgical methods, Fe(III) is usually removed from leachates through precipitation, but this is accompanied with the loss of adsorbed ions, prolonged washing steps and filtration issues. ${ }^{52}$ In the case of precious metals, the loss of absorbed ions can have a significant impact on the economic achievability of the process. Moreover, the precipitates are most often not suited for iron recovery and are landfilled. ${ }^{53,54}$ After combination of the raffinate and scrubbing solutions, sufficiently high $\mathrm{Cu}(\mathrm{II})$ and $\mathrm{Fe}(\mathrm{III})$ concentrations $\left(0.5-3 \mathrm{~g} \mathrm{~L}^{-1}\right)$ can be expected to allow their recovery. 

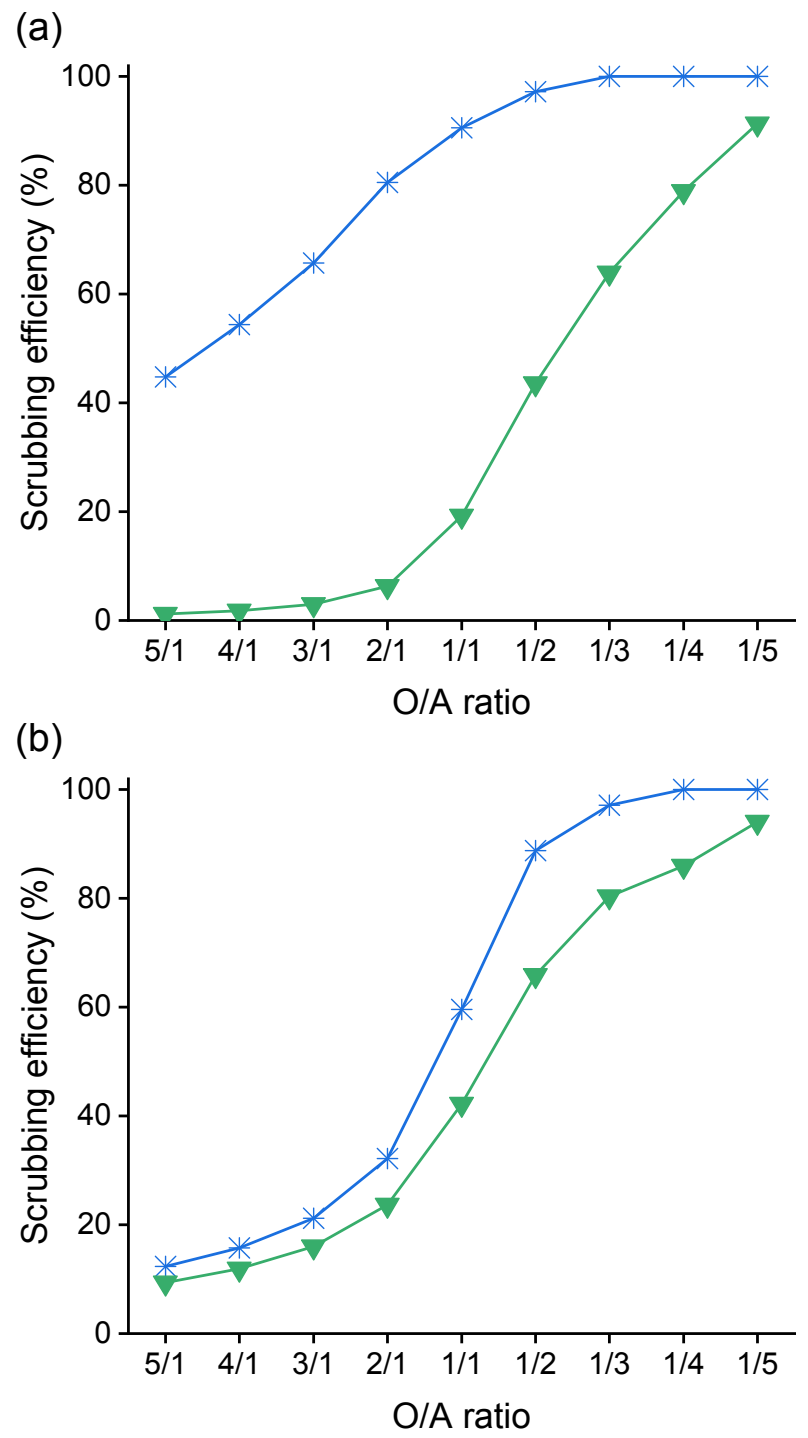

Figure 4: Scrubbing efficiency of Cu(II) (*) and $\mathrm{Fe}(\mathrm{III})$ ( $\mathbf{\nabla}$ ) from (a) [A336][Cl] and (b) [A336][Br] using water as a function of the O/A volume ratio. Conditions: $2500 \mathrm{rpm}, 60 \mathrm{~min}$, room temperature. 
Table 2: Metal concentrations in ppm in the scrub solutions and cumulative scrubbing efficiencies in \% (in parentheses) of Pd(II), Au(II), Cu(II) and Fe(III) from [A336][Cl] and $[A 336][B r]$ in a three-stage scrubbing procedure using water in an O/A volume ratio of 1/3. Conditions: 2500 rpm, 60 min, room temperature.

\begin{tabular}{lllll}
\hline & \multicolumn{4}{c}{$\begin{array}{c}\text { Metal concentrations in ppm } \\
\text { (cumulative stripping efficiency in \%) }\end{array}$} \\
\hline Stage & Pd(II) ${ }^{\S}$ & $\mathrm{Au}(\mathrm{III})^{\S}$ & $\mathrm{Cu}(\mathrm{II})^{\S}$ & $\mathrm{Fe}(\mathrm{III})^{\S}$ \\
\hline$[\mathrm{A} 336][\mathrm{Cl}]$ & & & & \\
1 & n.d. & n.d. & $1524(99)$ & $2221(64)$ \\
2 & n.d. & n.d. & $17(100)$ & $1284(100)$ \\
3 & n.d. & n.d. & n.d. $(100)$ & $10(100)$ \\
{$[$ A336][Br] } & & & & \\
1 & n.d. & n.d. & $1510(95)$ & $5133(76)$ \\
2 & n.d. & n.d. & $126(100)$ & $1586(99)$ \\
3 & n.d. & n.d. & n.d. $(100)$ & $24(100)$ \\
\hline
\end{tabular}

$\S$ Initial organic metal concentrations: 75 ppm Pd(II), 150 ppm Au(III), $4600 \mathrm{ppm}$ $\mathrm{Cu}(\mathrm{II})$ and 10500 ppm Fe(III) for [A336][Cl]; 75 ppm Pd(II), 150 ppm Au(III), 4900 ppm $\mathrm{Cu}(\mathrm{II})$ and $20200 \mathrm{ppm} \mathrm{Fe}(\mathrm{III})$ for [A336][Br].

* n.d. denotes 'not detected'.

Selective stripping of $A u(I I I)$ and Pd(II) from the scrubbed organic phase

After the scrubbing of both $\mathrm{Cu}(\mathrm{II})$ and $\mathrm{Fe}(\mathrm{III})$, the metals of interest (i.e. $\mathrm{Au}(\mathrm{III})$ and $\mathrm{Pd}(\mathrm{II})$ ) remain in the ionic liquid phases from which they need to be recovered. In a first scoping experiment, the performance of different stripping agents was tested on loaded [A336][Cl] and [A336][Br] containing $200 \mathrm{mg} \mathrm{L}^{-1} \mathrm{Au}(\mathrm{III})$ and $\mathrm{Pd}(\mathrm{II})$ (Figure 5). The loaded organic phases were prepared through the quantitative extraction of $\mathrm{Au}(\mathrm{III})$ and $\mathrm{Pd}(\mathrm{II})$ from $1 \mathrm{~mol} \mathrm{~L}^{-1} \mathrm{HCl}$ or $\mathrm{HBr}$, respectively, using a $\mathrm{O} / \mathrm{A}$ volume ratio of 1 . For $[\mathrm{A} 336][\mathrm{Cl}]$, the use of 
ethylenediaminetetraacetic acid (EDTA) allows for the selective and relatively quantitative stripping of $\mathrm{Pd}(\mathrm{II})$ while for $[\mathrm{A} 336][\mathrm{Br}]$ ammonia solution $\left(\mathrm{NH}_{3, \mathrm{aq}}\right)$ can be used. In both cases, the use of sodium sulfite $\left(\mathrm{Na}_{2} \mathrm{SO}_{3}\right)$ resulted in the stripping of $\mathrm{Au}(\mathrm{III})$ although the efficiency is significantly higher for the bromide system (i.e. 38 and $82 \%$, respectively). It must be noted that the use of $\mathrm{Na}_{2} \mathrm{SO}_{3}$ resulted in the reduction of $\mathrm{Pd}(\mathrm{II})$ and precipitation of palladium metal, which indicates that the order of stripping is essential. Pd(II) must be stripped prior to $\mathrm{Au}(\mathrm{III})$ when $\mathrm{Na}_{2} \mathrm{SO}_{3}$ is used for the latter. The stripping of $\mathrm{Au}(\mathrm{III})$ is facilitated through the formation of the $\mathrm{Au}(\mathrm{I})$ sulfite complex $\left[\mathrm{Au}\left(\mathrm{SO}_{3}\right)_{2}\right]^{3-}$, which is extremely stable as long as the $\mathrm{pH}$ is high enough $(>6) .{ }^{55}$

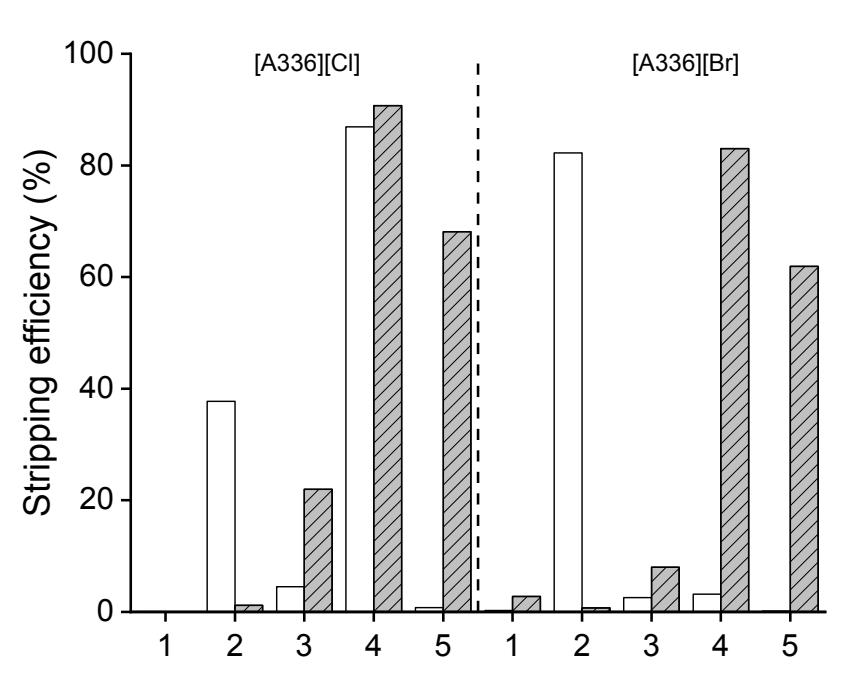

Figure 5: Stripping of $200 \mathrm{mg} \mathrm{L}^{-1} \mathrm{Au}(\mathrm{III})$ (white) and $200 \mathrm{mg} \mathrm{L}^{-1} \mathrm{Pd}(\mathrm{II})$ (grey, dashed) from [A336][Cl] (left) and [A336][Br] (right) using: (1) $1 \mathrm{~mol} \mathrm{~L}^{-1} \mathrm{Na}_{2} \mathrm{~S}_{2} \mathrm{O}_{3}$; (2) $1 \mathrm{~mol} \mathrm{~L}^{-1}$ $\mathrm{Na}_{2} \mathrm{SO}_{3}$; (3) $1 \mathrm{~mol} \mathrm{~L}^{-1}\left(\mathrm{NH}_{2}\right)_{2} \mathrm{CS}$ in $5 \% \mathrm{HCl}$; (4) $1 \mathrm{~mol} \mathrm{~L}^{-1} \mathrm{NH}_{3}$; (5) $0.5 \mathrm{~mol} \mathrm{~L}^{-1}$ EDTA at pH 13.0. Conditions: $2500 \mathrm{rpm}, 60 \mathrm{~min}$, room temperature, $O / A=1$. 
The stripping of $\mathrm{Pd}(\mathrm{II})$ was studied for both [A336][Cl] and [A336][Br] using loaded organic phases obtained after an extraction using the optimized procedure (i.e. $0.5 \mathrm{~mol} \mathrm{~L}^{-1} \mathrm{HCl}$ or $\mathrm{HBr}$, respectively, and a $\mathrm{O} / \mathrm{A}$ volume ratio of $1 / 3$ ) on a feed solution containing $50 \mathrm{mg} \mathrm{L}^{-1} \mathrm{Au}(\mathrm{III})$ and $25 \mathrm{mg} \mathrm{L}^{-1} \mathrm{Pd}(\mathrm{II})$. To study the stripping of $\mathrm{Au}(\mathrm{III})$, the organic phase was only loaded with $\mathrm{Au}(\mathrm{III}) \cdot \mathrm{Cu}(\mathrm{II})$ and $\mathrm{Fe}(\mathrm{III})$ were omitted from these experiments for simplicity and to avoid the necessity of the scrubbing procedure. For the stripping of $\mathrm{Pd}(\mathrm{II})$, the dependence of the stripping efficiency on the $\mathrm{pH}$ during the use of EDTA $\left(0.5 \mathrm{~mol} \mathrm{~L}^{-1}\right)$ for $[\mathrm{A} 336][\mathrm{Cl}]$ and on the $\mathrm{NH}_{3, \mathrm{aq}}$ concentration for [A336][Br] is shown in Figure 6. The dependence of $\mathrm{Au}(\mathrm{III})$ stripping on the $\mathrm{Na}_{2} \mathrm{SO}_{3}$ concentration is shown in Figure 7 for both [A336][Cl] and [A336][Br], its dependence on the O/A volume ratio was much less pronounced (Supporting Information, Figure S6).

For $[\mathrm{A} 336][\mathrm{Cl}]$, the stripping of $\mathrm{Pd}(\mathrm{II})$ was found to be highly dependent on the $\mathrm{pH}$ of the solution and less on the concentration of EDTA (Supporting Information, Figure S3). The stripping was only efficient when the $\mathrm{pH}$ was higher than 12 , but never reached completion (maximum aqueous $\mathrm{Pd}(\mathrm{II})$ concentration was $58 \mathrm{ppm}$ ). The steady increase in stripping efficiency around $\mathrm{pH} 11$ is the consequence of the final deprotonation of EDTA $\left(\mathrm{pK}_{\mathrm{a} 6}=10.24\right)$ which resulted in a more efficient binding of $\mathrm{Pd}(\mathrm{II}) .{ }^{56}$ However, such high $\mathrm{pH}$ values are detrimental for the stability and long-term usage of the ionic liquid which decomposes through a base-catalyzed Hofmann-type elimination reaction. ${ }^{57}$ Moreover, the stripping of $\mathrm{Au}(\mathrm{III})$ from [A336][Cl] using $\mathrm{Na}_{2} \mathrm{SO}_{3}$ did not reach high efficiencies, with $59 \%$ being the maximum (85 ppm $\mathrm{Au}(\mathrm{III})$ ). For $[\mathrm{A} 336][\mathrm{Br}]$, selective stripping of $\mathrm{Pd}(\mathrm{II})$ was possible at low $\mathrm{NH}_{3, \mathrm{aq}}$ concentrations and $0.2 \mathrm{~mol} \mathrm{~L}^{-1} \mathrm{NH}_{3, \mathrm{aq}}$ was chosen as the optimum, at higher concentrations $\mathrm{Au}(\mathrm{III})$ was stripped as well. In fact, a similar trend was observed when [A336][Cl] was treated with $\mathrm{NH}_{3 \text {,aq }}$ although the operating window for selective $\mathrm{Pd}(\mathrm{II})$ recovery was much smaller (Supporting Information, Figure S4) and EDTA remained the best option to strip Pd(II) from this ionic liquid. For [A336][Br], the stripping efficiency of $\mathrm{Pd}(\mathrm{II})$ could be increased from $93 \%$ 
to $99 \%$ through manipulation of the $\mathrm{O} / \mathrm{A}$ volume ratio with $2 / 1$ being the optimum (Supporting Information, Figure S5). This phase ratio allowed for an additional concentration of the $\mathrm{Pd}(\mathrm{II})$ (final aqueous concentration of $145 \mathrm{ppm}$ ) and a saving in chemicals. For $\mathrm{Au}(\mathrm{III})$, the stripping reached completion at $1.0 \mathrm{~mol} \mathrm{~L}^{-1} \mathrm{Na}_{2} \mathrm{SO}_{3}$ with an aqueous metal concentration of $138 \mathrm{ppm}$. The equilibrium $\mathrm{pH}$, which is indicated as the data labels in Figure 7, was well within the stability region of the $\left[\mathrm{Au}\left(\mathrm{SO}_{3}\right)_{2}\right]^{3-}$ complex at this $\mathrm{Na}_{2} \mathrm{SO}_{3}$ concentration. Note that the equilibrium $\mathrm{pH}$ was most likely lower than what would be observed when scrubbing and $\mathrm{Pd}$ stripping was performed prior, due to the back-extraction of co-extracted acid which would normally be scrubbed and/or neutralized by ammonia. 
(a)

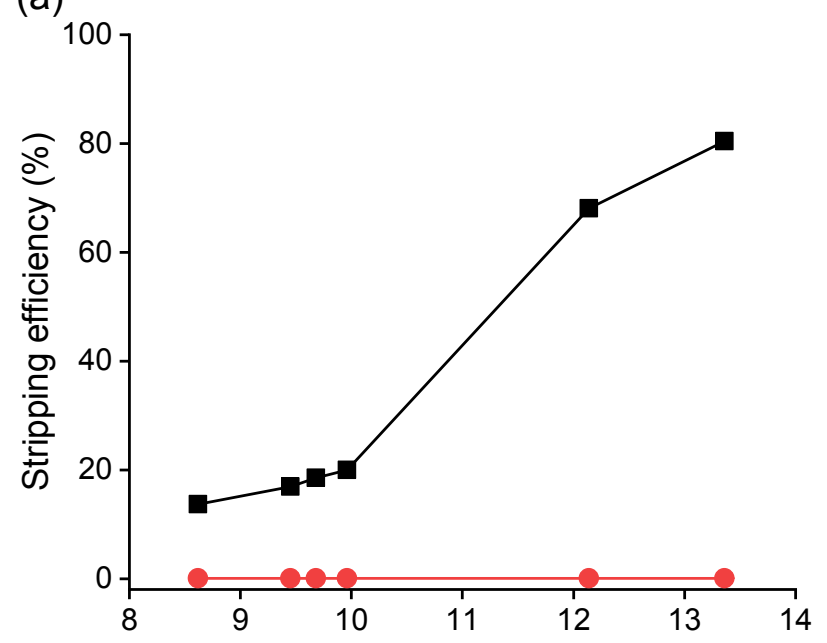

Equilibrium $\mathrm{pH}$

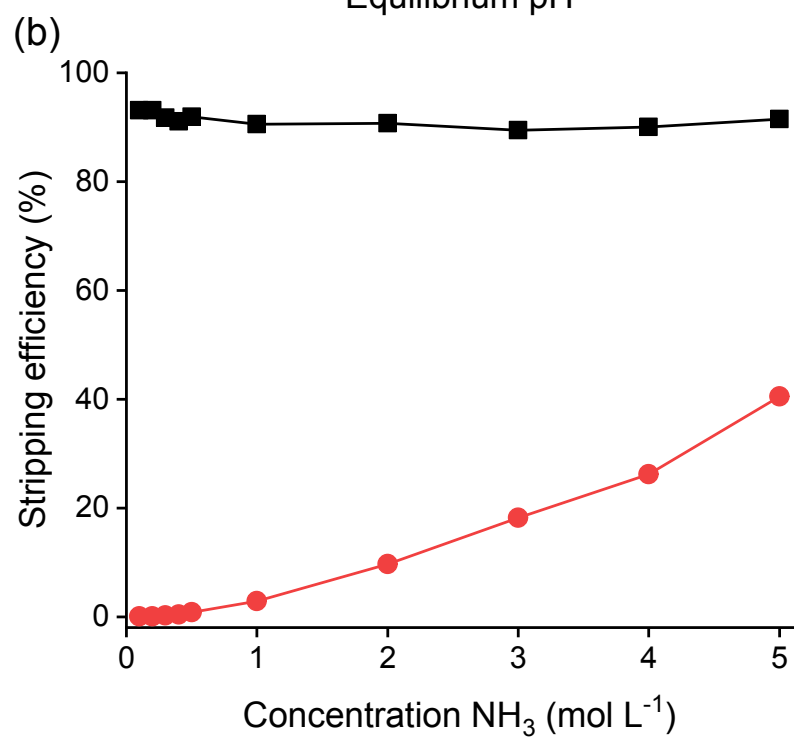

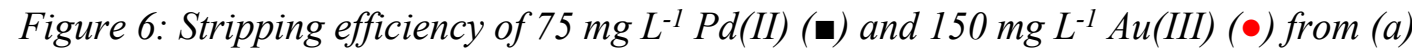
[A336][Cl] using $0.5 \mathrm{~mol} \mathrm{~L}^{-1}$ EDTA as a function of the $\mathrm{pH}$ (adjusted using a few drops of concentrated $\mathrm{NaOH}$ ) and (b) $[\mathrm{A336}][\mathrm{Br}]$ as a function of $\mathrm{NH}_{3}$ concentration. Conditions: $2500 \mathrm{rpm}, 60 \mathrm{~min}$, room temperature, $\mathrm{O} / \mathrm{A}=1$. 


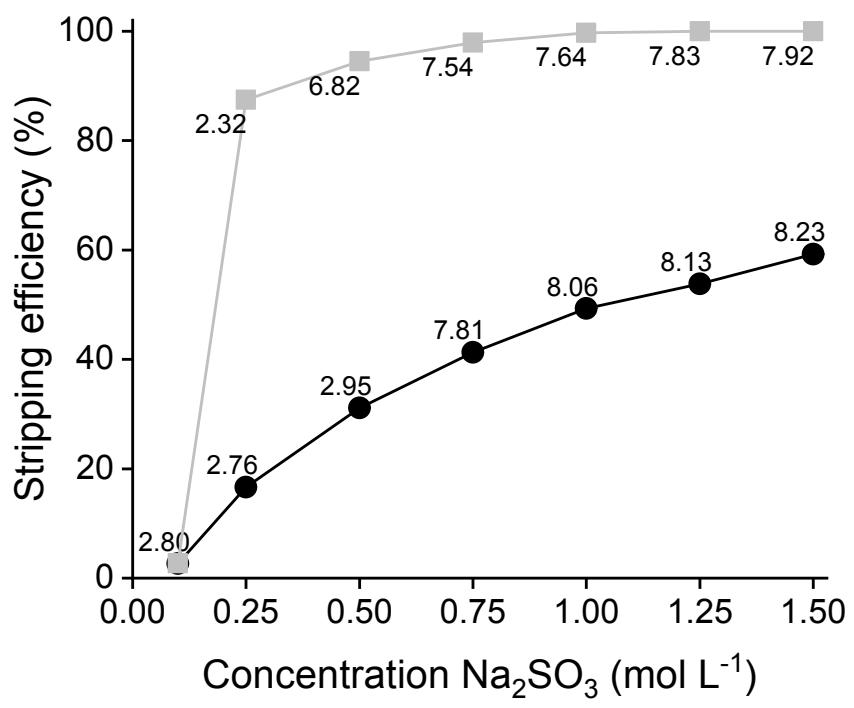

Figure 7: Stripping efficiency of $150 \mathrm{mg} \mathrm{L}^{-1} \mathrm{Au}(\mathrm{III})$ from [A336][Cl] (•) and [A336][Br] ( $\square$ ) as a function of the $\mathrm{Na}_{2} \mathrm{SO}_{3}$ concentration. The labels indicate the equilibrium $\mathrm{pH}$ values. Conditions: $2500 \mathrm{rpm}, 60 \mathrm{~min}$, room temperature, $\mathrm{O} / \mathrm{A}=1$.

\section{Conceptual separation flowsheet}

Based on the preceding discussion of the extraction, scrubbing and stripping behavior of $\mathrm{Cu}(\mathrm{II}), \mathrm{Fe}(\mathrm{III}), \mathrm{Au}(\mathrm{III})$ and $\mathrm{Pd}(\mathrm{II})$ with [A336][Cl] and [A336][Br], it can be concluded that the use of $[\mathrm{A} 336][\mathrm{Br}]$ is preferred over $[\mathrm{A} 336][\mathrm{Cl}]$ for this application, for three main reasons. First, the extraction of $\mathrm{Pd}(\mathrm{II})$ by $[\mathrm{A} 336][\mathrm{Cl}]$ at low acid concentrations is not entirely efficient, which can hamper the economic feasibility of the process. Secondly, the selective stripping of Pd(II) from [A336][Cl] using EDTA requires a high $\mathrm{pH}(>12)$ which decomposes the ionic liquid. Additionally, EDTA is resistant to chemical and biological degradation and its release would cause environmental issues. ${ }^{58}$ The much cheaper ammonia solution is as such preferred, which can be used to selectively recover Pd(II) from [A336][Br]. Thirdly, the stripping of $\mathrm{Au}(\mathrm{III})$ using $\mathrm{Na}_{2} \mathrm{SO}_{3}$ is less efficient from [A336][Cl] than from [A336][Br]. 
Figure 8 summarizes a conceptual flowsheet for the treatment of a solution which contains large amounts of both $\mathrm{Cu}(\mathrm{II})$ and $\mathrm{Fe}(\mathrm{III})$, and minor amounts of the precious metals $\mathrm{Au}(\mathrm{III})$ and Pd(II). The expected metal concentrations of all involved aqueous phases are shown in Table 3. First, the solution is subjected to an extraction by [A336][Br] at $0.5 \mathrm{~mol} \mathrm{~L}^{-1} \mathrm{HBr}$ and a $\mathrm{O} / \mathrm{A}$ volume ratio of $1 / 3$. The co-extracted $\mathrm{Cu}$ (II) and $\mathrm{Fe}(\mathrm{III})$ can then easily be scrubbed in three stages using $\mathrm{H}_{2} \mathrm{O}$ at a $\mathrm{O} / \mathrm{A}$ volume ratio of $1 / 3$. At this point, the decision could be made to recycle the ionic liquid to the extraction stage and to allow the organic phase to be loaded with more $\mathrm{Au}(\mathrm{III})$ and $\mathrm{Pd}(\mathrm{II})$ before stripping. This option is indicated with a dashed line as it was not explored further. Next, $\mathrm{Pd}(\mathrm{II})$ can be selectively stripped using $0.2 \mathrm{~mol} \mathrm{~L}^{-1}$ ammonia solution and an $\mathrm{O} / \mathrm{A}$ volume ratio of $2 / 1$. $\mathrm{Pd}(\mathrm{II})$ can be recovered from such solutions by precipitation as $\mathrm{Pd}\left(\mathrm{NH}_{3}\right)_{2} \mathrm{Cl}_{2}$ through the addition of $\mathrm{HCl}$. Thermal decomposition of this precipitate will result in palladium sponge. ${ }^{59} \mathrm{Au}(\mathrm{III})$ can be stripped using $1.0 \mathrm{~mol} \mathrm{~L}^{-1} \mathrm{Na}_{2} \mathrm{SO}_{3}$ and an $\mathrm{O} / \mathrm{A}$ volume ratio of $1 / 1$. Acidification of the sulfite strip solution will result in the precipitation of metallic gold. ${ }^{55}$ Finally, the ionic liquid can be regenerated before being recycled to the extraction stage. This can possibly be done through contacting it with a fresh $\mathrm{NaBr}$ solution as some chloride uptake is expected (Supporting Information, Figure S2). The regeneration and recycling of the IL was not studied for this particular case, although the recyclability of ILs after proper regeneration steps has been shown in other solvent extraction research. ${ }^{60-62}$ It should also be noted that, based on the results in Figure 1, this flowsheet can in principle easily be extended to solutions containing $\mathrm{Ni}$ (II) as it is not extracted and remains in the raffinate. 


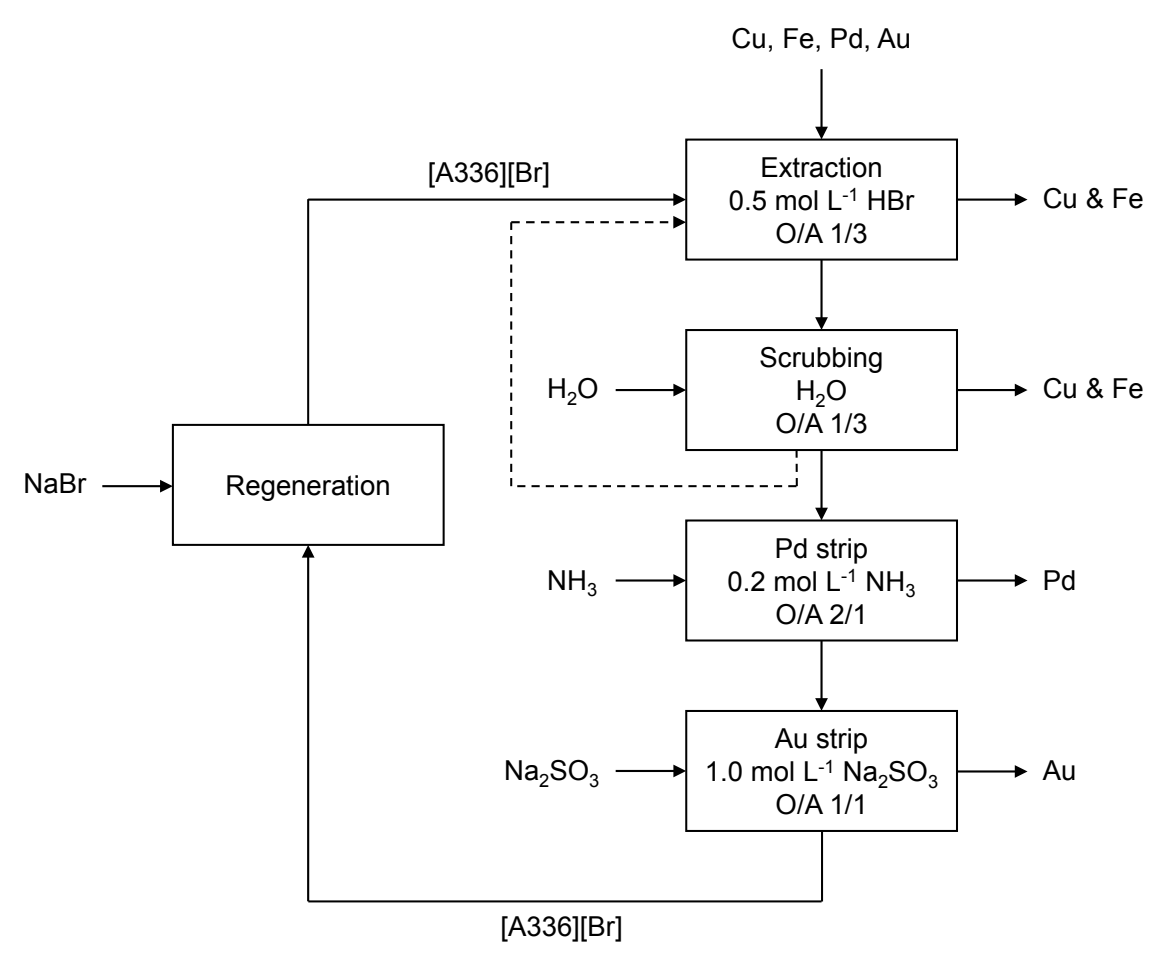

Figure 8: Conceptual flowsheet for recovery of Au(III) and Pd(II) from solutions containing high concentrations of $\mathrm{Cu}(\mathrm{II})$ and $\mathrm{Fe}(I I I)$ using the ionic liquid [A336][Br]. 
Table 3: Indicative aqueous metal concentrations throughout the different steps of the developed separation flowsheet for Pd(II), $\mathrm{Au}(I I I), \mathrm{Cu}(I I)$ and $\mathrm{Fe}(I I I)$.

\begin{tabular}{|c|c|c|c|c|}
\hline & $\operatorname{Pd}(\mathrm{II})(\mathrm{ppm})$ & $\mathrm{Au}(\mathrm{III})(\mathrm{ppm})$ & $\mathrm{Cu}(\mathrm{II})\left(\mathrm{g} \mathrm{L}^{-1}\right)$ & $\mathrm{Fe}(\mathrm{III})\left(\mathrm{g} \mathrm{L}^{-1}\right)$ \\
\hline Feed solution & 24 & 46 & 3.2 & 10.7 \\
\hline $\begin{array}{l}\text { Raffinate after extraction to } \\
\text { [A336][Br] } \\
\left(0.5 \mathrm{~mol} \mathrm{~L}^{-1} \mathrm{HBr}, \mathrm{O} / \mathrm{A}=1 / 3\right)\end{array}$ & n.d.* & n.d. & 1.6 & 4.0 \\
\hline $\begin{array}{l}1^{\text {st }} \text { scrubbing step } \\
\left(\mathrm{H}_{2} \mathrm{O}, \mathrm{O} / \mathrm{A}=1 / 3\right)\end{array}$ & n.d. & n.d. & 1.5 & 5.1 \\
\hline $\begin{array}{l}2^{\text {nd }} \text { scrubbing step } \\
\left(\mathrm{H}_{2} \mathrm{O}, \mathrm{O} / \mathrm{A}=1 / 3\right)\end{array}$ & n.d. & n.d. & 0.1 & 1.6 \\
\hline $\begin{array}{l}3^{\text {rd }} \text { scrubbing step } \\
\left(\mathrm{H}_{2} \mathrm{O}, \mathrm{O} / \mathrm{A}=1 / 3\right)\end{array}$ & n.d. & n.d. & n.d. & $>0.1$ \\
\hline $\begin{array}{l}\mathrm{Pd}(\mathrm{II}) \text { stripping } \\
\left(0.2 \mathrm{~mol} \mathrm{~L}^{-1} \mathrm{NH}_{3}, \mathrm{O} / \mathrm{A}=2 / 1\right)\end{array}$ & 144 & n.d. & n.d. & n.d. \\
\hline $\begin{array}{l}\mathrm{Au}(\mathrm{III}) \text { stripping } \\
\left(1.0 \mathrm{~mol} \mathrm{~L}-1 \mathrm{Na}_{2} \mathrm{SO}_{3}, \mathrm{O} / \mathrm{A}=\right. \\
1 / 1)\end{array}$ & n.d. & 138 & n.d. & n.d. \\
\hline
\end{tabular}

* n.d. denotes 'not detected'.

The developed process for the separation of the precious metals $\mathrm{Au}(\mathrm{III})$ and $\mathrm{Pd}(\mathrm{II})$ from the base metals $\mathrm{Cu}(\mathrm{II})$ and $\mathrm{Fe}(\mathrm{III})$ can provide some advantages over the conventional separation processes. Firstly, the flowsheet makes use of only one extracting phase whereas often a series of multiple extractants are in use for precious metal separations and the process can as such be considered less complex. In commercial processes extractants such as MIBK and $\beta$-hydroxyl oxime are in use for $\mathrm{Au}(\mathrm{III})$ and $\mathrm{Pd}$ (II) respectively. ${ }^{59,63}$ Other extractants such as Cyanex 272 and LIX 63 have also been studied ${ }^{64}$ In addition to this, the used extracting phase is an undiluted ionic liquid and volatile and flammable organic solvents are avoided entirely providing an 
advantage in terms of safety (e.g. MIBK has a flash point of $14{ }^{\circ} \mathrm{C}$ ). Secondly, not only air pollution but also contamination of the aqueous phase can be expected to be low. The aqueous solubility of $[\mathrm{A} 336][\mathrm{Cl}]$ has been studied and is low $(<900 \mathrm{ppm}) .{ }^{65}$ The solubility of [A336][Br] can be expected to be even less due to its more apolar nature. This is backed up by its significantly lower saturation water content (Supporting Information, Table S1). Thirdly, making use of a bromide ionic liquid, the process is capable of accepting bromide containing leach liquors without degradation of the ionic liquid. The presence of nitrates would still result in the anion exchange of the ionic liquid (cfr. the Hofmeister series) but is expected to be less severe and more easily reversed as compared with a chloride ionic liquid. And finally, base metals are partly co-extracted and subsequently scrubbed instead of precipitated as performed conventionally. This approach avoids filtration issues and any loss of precious metals due to adsorption to the precipitate. Both iron and copper remain in solution in sufficiently high concentration allowing their recovery which is often not the case when precipitation is applied.

Besides these possible advantages, it is important to make some side notes. Firstly, the process has been developed on small liquid volumes and upscaling has not been considered in current research. Some of the undesirable characteristic of ionic liquids (high viscosity, reduced mass transfer rates, etc...) will become more prominent when larger liquid volumes are applied. Secondly, only model solutions were studied without suspended solids, impurity metals, dissolved solids, high acid/salt concentrations or combinations of acids which are expected for real leachates. The developed process will hence be subject to some changes when real solutions are considered. Taking into account these considerations, the separation flowsheet might find interest in the purification of WEEE leachates or gold ore leachates. Other applications can include analytical purposes of small scale samples. 


\section{Conclusion}

In this research, the extraction behavior of $\mathrm{Pt}(\mathrm{IV}), \mathrm{Pd}(\mathrm{II}), \mathrm{Rh}(\mathrm{III}), \mathrm{Au}(\mathrm{III}), \mathrm{Cu}(\mathrm{II}), \mathrm{Fe}(\mathrm{III})$ and $\mathrm{Ni}(\mathrm{II})$ in different halide media by the ionic liquids [A336][Cl], [A336][Br] and [A336][I] was compared. In general, the precious metals are extracted very efficiently over the entire halide concentration range while the base metals are not. The chloride and bromide systems showed promising characteristics for the separation of $\mathrm{Pt}(\mathrm{IV}), \mathrm{Pd}(\mathrm{II})$ and $\mathrm{Au}(\mathrm{III})$ from $\mathrm{Cu}(\mathrm{II}), \mathrm{Fe}(\mathrm{III})$ and $\mathrm{Ni}$ (II) while the iodide system allowed for the convenient single-step separation of the precious metals $\mathrm{Pt}(\mathrm{IV})$ and $\mathrm{Pd}(\mathrm{II})$ from the base metals $\mathrm{Fe}(\mathrm{III})$ and $\mathrm{Ni}(\mathrm{II})$. This opportunity was studied more in depth for the separation and recovery of $\mathrm{Au}(\mathrm{III})$ and $\mathrm{Pd}(\mathrm{II})$ from $\mathrm{Cu}(\mathrm{II})$ and $\mathrm{Fe}(\mathrm{III})$ rich solutions. In terms of extraction performance and scrubbing characteristics, the chloride and bromide media performed similarly and allowed an easy separation of $\mathrm{Au}(\mathrm{III})$ and Pd(II) from $\mathrm{Cu}(\mathrm{II})$ and $\mathrm{Fe}(\mathrm{III})$. However, [A336][Br] showed a superior stripping behavior over [A336][Cl], providing an easy, quantitative separation and recovery of $\mathrm{Au}(\mathrm{III})$ and $\mathrm{Pd}(\mathrm{II})$. The research on the extraction behavior of $\mathrm{Pt}(\mathrm{IV}), \mathrm{Pd}(\mathrm{II}), \mathrm{Rh}(\mathrm{III}), \mathrm{Au}(\mathrm{III}), \mathrm{Cu}(\mathrm{II}), \mathrm{Fe}(\mathrm{III})$ and $\mathrm{Ni}(\mathrm{II})$ in the different halides provides a convenient overview of the metal separation possibilities in these halides using basic extractants. Furthermore, the fact that the bromide system allowed for a more efficient metal separation in this case study underlines the usefulness of broadening solvent extraction research to media other than the conventional chloride ones. 


\section{Supporting Information (SI)}

The Supporting Information is available free of charge on the ACS Publications website and includes: properties of synthesized ionic liquids, TXRF spectra of the scrubbed [A336][Cl] and [A336][Br], influence of the EDTA concentration on the stripping of Pd(II) from $[\mathrm{A} 336][\mathrm{Cl}]$, dependence of the stripping of $\mathrm{Pd}(\mathrm{II})$ from $[\mathrm{A} 336][\mathrm{Br}]$ on the $\mathrm{O} / \mathrm{A}$ volume ratio using $0.2 \mathrm{~mol}$ $\mathrm{L}^{-1} \mathrm{NH}_{3}$, stripping of $\mathrm{Pd}(\mathrm{II})$ and $\mathrm{Au}(\mathrm{III})$ from [A336][Cl] as a function of $\mathrm{NH}_{3}$ concentration, dependence of the stripping of $\mathrm{Au}(\mathrm{III})$ using 1.5 and $1.0 \mathrm{~mol} \mathrm{~L}^{-1} \mathrm{Na}_{2} \mathrm{SO}_{3}$ from [A336][Cl] and [A336][Br], respectively, on the $\mathrm{O} / \mathrm{A}$ volume ratio.

\section{Acknowledgements}

The authors thank the KU Leuven for financial support (project C24/18/042, ISOMER).

\section{Conflict of interest}

There are no conflicts to declare. 


\section{References}

(1) Rydberg, J. Solvent Extraction Principles and Practice, Revised and Expanded; CRC Press: New York, 2004.

(2) Seddon, K. R. Ionic Liquids for Clean Technology. J. Chem. Technol. Biotechnol. 1997, 68 (4), 351-356. https://doi.org/10.1002/(SICI)1097-4660(199704)68:4<351::AIDJCTB613>3.0.CO;2-4.

(3) Plechkova, N. V.; Seddon, K. R. Applications of Ionic Liquids in the Chemical Industry. Chem. Soc. Rev. 2007, 37 (1), 123-150. https://doi.org/10.1039/B006677J.

(4) Chubb, J. N.; Lagos, P.; Lienlaf, J. Electrostatic Safety during the Solvent Extraction of Copper. J. Electrost. 2005, 63 (2), 119-127. https://doi.org/10.1016/j.elstat.2004.09.002.

(5) Wellens, S.; Thijs, B.; Binnemans, K. An Environmentally Friendlier Approach to Hydrometallurgy: Highly Selective Separation of Cobalt from Nickel by Solvent Extraction with Undiluted Phosphonium Ionic Liquids. Green Chem. 2012, 14 (6), 1657 1665. https://doi.org/10.1039/C2GC35246J.

(6) Riaño, S.; Binnemans, K. Extraction and Separation of Neodymium and Dysprosium from Used NdFeB Magnets: An Application of Ionic Liquids in Solvent Extraction towards the Recycling of Magnets. Green Chem. 2015, 17 (5), 2931-2942. https://doi.org/10.1039/C5GC00230C.

(7) Firmansyah, M. L.; Kubota, F.; Yoshida, W.; Goto, M. Application of a Novel Phosphonium-Based Ionic Liquid to the Separation of Platinum Group Metals from Automobile Catalyst Leach Liquor. Ind. Eng. Chem. Res. 2019, 58 (9), 3845-3852. https://doi.org/10.1021/acs.iecr.8b05848.

(8) Firmansyah, M. L.; Kubota, F.; Goto, M. Solvent Extraction of Pt(IV), Pd(II), and Rh(III) with the Ionic Liquid Trioctyl(Dodecyl) Phosphonium Chloride. J. Chem. Technol. Biotechnol. 2018, 93 (6), 1714-1721. https://doi.org/10.1002/jctb.5544.

(9) Seeley, F. G.; Crouse, D. J. Extraction of Metals from Chloride Solutions and Amines. J. Chem. Eng. Data 1966, 11 (3), 424-429. https://doi.org/10.1021/je60030a043.

(10) Aprahamian, V. H.; Demopoulos, G. P. The Solution Chemistry and Solvent Extraction Behaviour of Cu, Fe, Ni, Zn, Pb, Sn, Ag, As, Sb, Bi, Se and Te in Acid Chloride Solutions Reviewed from the Standpoint of PGM Refining. Miner. Process. Extr. Metall. Rev. 1995, 14 (3-4), 143-167. https://doi.org/10.1080/08827509508914122.

(11) Lommelen, R.; Vander Hoogerstraete, T.; Onghena, B.; Billard, I.; Binnemans, K. Model for Metal Extraction from Chloride Media with Basic Extractants: A Coordination Chemistry Approach. Inorg. Chem. 2019, 58 (18), 12289-12301. https://doi.org/10.1021/acs.inorgchem.9b01782.

(12) Deferm, C.; Onghena, B.; Hoogerstraete, T. V.; Banerjee, D.; Luyten, J.; Oosterhof, H.; Fransaer, J.; Binnemans, K. Speciation of Indium(III) Chloro Complexes in the Solvent Extraction Process from Chloride Aqueous Solutions to Ionic Liquids. Dalton Trans. 2017, 46 (13), 4412-4421. https://doi.org/10.1039/C7DT00618G.

(13) Nakamura, K.; Ozawa, T. Spectrophotometric Determination of Micro Amounts of Mercury, Cadmium, and Zinc by Stepwise Extraction with Tribenzylamine. Anal. Chim. Acta 1976, 86, 147-156. https://doi.org/10.1016/S0003-2670(01)83028-2.

(14) Sherif, Sh. A.; Abdel-Gawad, A. S.; El-Wakil, A. M. Solvent Extraction of Ga(III) and In(III) from Aqueous Halide Media by Adogen-364. Talanta 1970, 17 (2), 137-142. https://doi.org/10.1016/0039-9140(70)80114-X.

(15) Mojski, M. Extraction of Gold, Palladium and Platinum from Chloride, Bromide and Iodide Solution with Di-n-Octyl Sulphide (DOS) in Cyclohexane. Talanta 1978, 25 (3), 163-165. https://doi.org/10.1016/0039-9140(78)80107-6. 


\section{Reractions Condemns Cations to the Most Weakly Interacting Anions and Dictates Reaction Equilibrium. Green Chem. 2018, 20 (18), 4277-4286.} https://doi.org/10.1039/C8GC01869C.

(25) Tuncuk, A.; Stazi, V.; Akcil, A.; Yazici, E. Y.; Deveci, H. Aqueous Metal Recovery Techniques from E-Scrap: Hydrometallurgy in Recycling. Miner. Eng. 2012, 25 (1), 28 37. https://doi.org/10.1016/j.mineng.2011.09.019.

(26) Abdelbasir, S. M.; Hassan, S. S. M.; Kamel, A. H.; El-Nasr, R. S. Status of Electronic Waste Recycling Techniques: A Review. Environ. Sci. Pollut. Res. 2018, 25 (17), 16533-16547. https://doi.org/10.1007/s11356-018-2136-6.

(27) Benguerel, E.; Demopoulos, G. P.; Harris, G. B. Speciation and Separation of Rhodium (III) from Chloride Solutions: A Critical Review. Hydrometallurgy 1996, 40 (1), 135 152. https://doi.org/10.1016/0304-386X(94)00086-I.

(28) Svecova, L.; Papaiconomou, N.; Billard, I. Quantitative Extraction of Rh(III) Using Ionic Liquids and Its Simple Separation from Pd(II). Dalton Trans. 2016, 45 (38), 15162 15169. https://doi.org/10.1039/C6DT02384C.

(29) Svecova, L.; Papaïconomou, N.; Billard, I. Rh(III) Aqueous Speciation with Chloride as a Driver for Its Extraction by Phosphonium Based Ionic Liquids. Molecules 2019, 24 (7), 1391. https://doi.org/10.3390/molecules24071391.

(30) Dreher, T. M.; Demopoulos, G. P. The Conversion of Rh(III) Chlorocomplexes to Bromocomplexes and Their Solvent Extraction Behaviour. Solvent Extr. Ion Exch. 1999, 17 (5), 1231-1253. https://doi.org/10.1080/07366299908934645. 
(31) Morris, D. F. C.; Wilson, A. R. Application of Dinonyl Naphthalene Sulphonic Acid in Solution in N-Heptane as a Liquid Cation-Exchanger to a Study of the Formation of Iron(III) Chloride and Iron(III) Bromide Complexes. J. Inorg. Nucl. Chem. 1969, 31 (5), 1532-1536. https://doi.org/10.1016/0022-1902(69)80276-9.

(32) Lister, M.; Rosenblum, P. Some Equilibrium Constants of Transition Metal Halides. Can. J. Chem. 1960, 38, 1827-1836. https://doi.org/10.1139/v60-248.

(33) Liu, W.; Migdisov, A.; Williams-Jones, A. The Stability of Aqueous Nickel(II) Chloride Complexes in Hydrothermal Solutions: Results of UV-Visible Spectroscopic Experiments. Geochim. Cosmochim. Acta 2012, 94, 276-290. https://doi.org/10.1016/j.gca.2012.04.055.

(34) Antelman, M. The Encyclopedia of Chemical Electrode Potentials; Springer Science \& Business Media: Berlin, 2012.

(35) Usher, A.; McPhail, D. C.; Brugger, J. A Spectrophotometric Study of Aqueous Au(III) Halide-Hydroxide Complexes at $25-80^{\circ} \mathrm{C}$. Geochim. Cosmochim. Acta 2009, 11 (73), 3359-3380. https://doi.org/10.1016/j.gca.2009.01.036.

(36) Ryan, J. L. Weak or Unstable Iodo Complexes. II. Iodo Complexes of Titanium(IV), Iron(III), and Gold(III). Inorg. Chem. 1969, 8 (10), 2058-2062. https://doi.org/DOI: 10.1021/ic50080a004.

(37) Holleman, A. F.; Wiberg, E.; Wiberg, N. Inorganic Chemistry; Academic Press: Cambridge, 2001.

(38) Beamish, F. E.; Dale, J. Determination of Palladium by Means of Potassium Iodide. Ind. Eng. Chem. Anal. Ed. 1938, 10 (12), 697-698. https://doi.org/10.1021/ac50128a015.

(39) Conry, R. R. Copper: Inorganic \& Coordination Chemistry. In Encyclopedia of Inorganic Chemistry; John Wiley \& Sons: Hoboken, 2006.

(40) Kauffman, G. B.; Fang, L. Y.; Viswanathan, N.; Townsend, G. Purification of Copper (i) Iodide. In Inorganic Syntheses; Wiley-Blackwell: Hoboken, 1983; Vol. 22, pp 101102. https://doi.org/10.1002/9780470132531.ch20.

(41) Skoog, D. A.; West, D. M.; Crouch, S. R.; Holler, F. J. Fundamentals of Analytical Chemistry; Thomson-Brooks/Cole: Boston, 2004.

(42) Nicholls, D. The Chemistry of Iron, Cobalt and Nickel: Comprehensive Inorganic Chemistry; Pergamon Press: Oxford, 2013.

(43) Cucchiella, F.; D’Adamo, I.; Lenny Koh, S. C.; Rosa, P. Recycling of WEEEs: An Economic Assessment of Present and Future e-Waste Streams. Renew. Sustain. Energy Rev. 2015, 51, 263-272. https://doi.org/10.1016/j.rser.2015.06.010.

(44) Kaya, M. Recovery of Metals and Nonmetals from Electronic Waste by Physical and Chemical Recycling Processes. Waste Manag. 2016, 57, 64-90. https://doi.org/10.1016/j.wasman.2016.08.004.

(45) Hsu, E.; Barmak, K.; West, A. C.; Park, A.-H. A. Advancements in the Treatment and Processing of Electronic Waste with Sustainability: A Review of Metal Extraction and Recovery Technologies. Green Chem. 2019, 21 (5), 919-936. https://doi.org/10.1039/C8GC03688H.

(46) Abdelbasir, S. M.; El-Sheltawy, C. T.; Abdo, D. M. Green Processes for Electronic Waste Recycling: A Review. J. Sustain. Metall. 2018, 4 (2), 295-311. https://doi.org/10.1007/s40831-018-0175-3.

(47) Grant, K.; Goldizen, F. C.; Sly, P. D.; Brune, M.-N.; Neira, M.; van den Berg, M.; Norman, R. E. Health Consequences of Exposure to E-Waste: A Systematic Review. Lancet Glob. Health 2013, 1 (6), e350-e361. https://doi.org/10.1016/S2214109X(13)70101-3. 
(48) Kiddee, P.; Naidu, R.; Wong, M. H. Electronic Waste Management Approaches: An Overview. Waste Manag. 2013, 33 (5), 1237-1250. https://doi.org/10.1016/j.wasman.2013.01.006.

(49) Cui, J.; Zhang, L. Metallurgical Recovery of Metals from Electronic Waste: A Review. J. Hazard. Mater. 2008, $158 \quad$ (2), $228-256$. https://doi.org/10.1016/j.jhazmat.2008.02.001.

(50) Hageluken, C. Improving Metal Returns and Eco-Efficiency in Electronics Recycling a Holistic Approach for Interface Optimisation between Pre-Processing and Integrated Metals Smelting and Refining. Proc. 2006 IEEE Int. Symp. Electron. Environ. 2006, 218-223.

(51) Elding, L. I. Palladium(II) Halide Complexes. I. Stabilities and Spectra of Palladium(II) Chloro and Bromo Aqua Complexes. Inorganica Chim. Acta 1972, 6, 647-651. https://doi.org/10.1016/S0020-1693(00)91874-7.

(52) Demopoulos, G. P. Aqueous Precipitation and Crystallization for the Production of Particulate Solids with Desired Properties. Hydrometallurgy 2009, 96 (3), 199-214. https://doi.org/10.1016/j.hydromet.2008.10.004.

(53) Davey, P. T.; Scott, T. R. Removal of Iron from Leach Liquors by the "Goethite" Process. Hydrometallurgy 1976, 2 (1), 25-33. https://doi.org/10.1016/0304-386X(76)90011-6.

(54) Yazici, E.; Bas, A. D.; Deveci, H. Removal of Iron as Goethite from Leach Solutions of Waste of Printed Circuit Boards (WPCB). In Proceedings of the XXVII International Mineral Processing Congress - IMPC 2014; Santiago, 2014. https://doi.org/10.13140/2.1.2909.7929.

(55) Mironov, I. V.; Kharlamova, V. Yu. Properties of the Gold(I) Sulfite Complex in Acidic Chloride Solutions. Russ. J. Inorg. Chem. 2016, 61 (8), 1047-1053. https://doi.org/10.1134/S003602361608012X.

(56) Latscha, H. P.; Linti, G. W.; Klein, H. A. Analytische Chemie: Chemie-Basiswissen III; Springer-Verlag: Berlin, 2013.

(57) Lethesh, K. C.; Dehaen, W.; Binnemans, K. Base Stable Quaternary Ammonium Ionic Liquids. $R S C A d v$. 2013, 4 (9), 4472-4477. https://doi.org/10.1039/C3RA45126G.

(58) Gylienè, O.; Aikaite, J.; Nivinskienè, O. Recovery of EDTA from Complex Solution Using $\mathrm{Cu}(\mathrm{II})$ as Precipitant and $\mathrm{Cu}(\mathrm{II})$ Subsequent Removal by Electrolysis. J. Hazard. Mater. 2004, 116 (1), 119-124. https://doi.org/10.1016/j.jhazmat.2004.08.026.

(59) Crundwell, F.; Moats, M.; Ramachandran, V.; Robinson, T.; Davenport, W. G. Extractive Metallurgy of Nickel, Cobalt and Platinum Group Metals; Elsevier: Amsterdam, 2011.

(60) Onghena, B.; Binnemans, K. Recovery of Scandium(III) from Aqueous Solutions by Solvent Extraction with the Functionalized Ionic Liquid Betainium Bis(Trifluoromethylsulfonyl)Imide. Ind. Eng. Chem. Res. 2015, 54 (6), 1887-1898. https://doi.org/10.1021/ie504765v.

(61) Onghena, B.; Valgaeren, S.; Hoogerstraete, T. V.; Binnemans, K. Cobalt(II)/Nickel(II) Separation from Sulfate Media by Solvent Extraction with an Undiluted Quaternary Phosphonium Ionic Liquid. RSC Adv. 2017, 7 (57), 35992-35999. https://doi.org/10.1039/C7RA04753C.

(62) Riaño, S.; Petranikova, M.; Onghena, B.; Hoogerstraete, T. V.; Banerjee, D.; Foreman, M. R. S.; Ekberg, C.; Binnemans, K. Separation of Rare Earths and Other Valuable Metals from Deep-Eutectic Solvents: A New Alternative for the Recycling of Used NdFeB Magnets. RSC Adv. 2017, 7 (51), 32100-32113. https://doi.org/10.1039/C7RA06540J.

(63) Charlesworth, P. Separating the Platinum Group Metals by Liquid-Liquid Extraction. Platin. Met. Rev. 1981, 25 (3), 106-112. 
(64) Xing, W. D.; Lee, M. S.; Kim, Y. H. Separation of Gold(III) from Hydrochloric Acid Solution Containing Platinum(IV) and Palladium(II) by Solvent Extraction with Cyanex 272 and LIX 63. J. Ind. Eng. Chem. 2018, 59, 328-334. https://doi.org/10.1016/j.jiec.2017.10.039.

(65) Deferm, C.; Voorde, M. V. de; Luyten, J.; Oosterhof, H.; Fransaer, J.; Binnemans, K. Purification of Indium by Solvent Extraction with Undiluted Ionic Liquids. Green Chem. 2016, 18 (14), 4116-4127. https://doi.org/10.1039/C6GC00586A. 


\section{For Table of Contents Use Only}

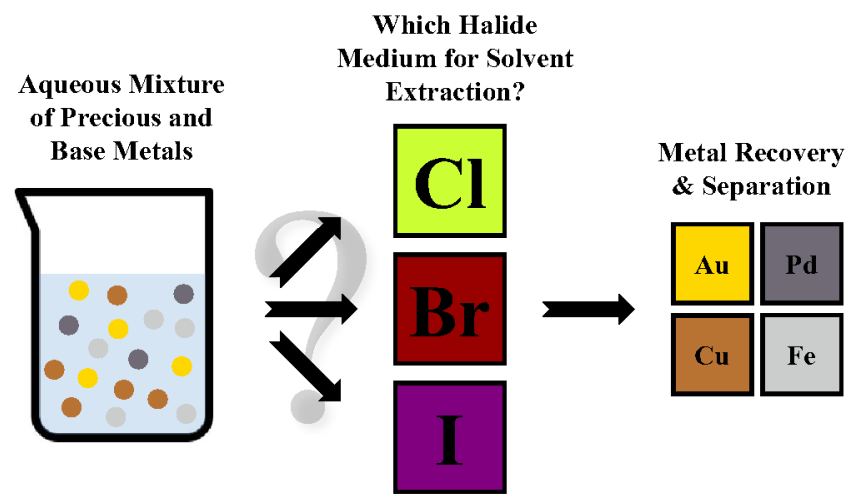

Synopsis: Based on the comparison of the metal extraction behavior of different halide ionic liquids, a separation procedure for the recovery of $\mathrm{Pd}(\mathrm{II})$ and $\mathrm{Au}(\mathrm{III})$ from $\mathrm{Cu}(\mathrm{II})$ and $\mathrm{Fe}(\mathrm{III})$ rich solutions was developed using a bromide ionic liquid. 